\title{
Abyssal Circulation Driven by Near-Boundary Mixing: Water Mass Transformations and Interior Stratification
}

\author{
HENRI F. DRAKE \\ MIT-WHOI Joint Program in Oceanography/Applied Ocean Science and Engineering, \\ Massachusetts Institute of Technology, Cambridge, Massachusetts \\ RAFFAELE FERRARI \\ Massachusetts Institute of Technology, Cambridge, Massachusetts \\ JÖRN CALLIES \\ California Institute of Technology, Pasadena, California
}

(Manuscript received 14 December 2019, in final form 2 June 2020)

\begin{abstract}
The emerging view of the abyssal circulation is that it is associated with bottom-enhanced mixing, which results in downwelling in the stratified ocean interior and upwelling in a bottom boundary layer along the insulating and sloping seafloor. In the limit of slowly varying vertical stratification and topography, however, boundary layer theory predicts that these upslope and downslope flows largely compensate, such that net water mass transformations along the slope are vanishingly small. Using a planetary geostrophic circulation model that resolves both the boundary layer dynamics and the large-scale overturning in an idealized basin with bottom-enhanced mixing along a midocean ridge, we show that vertical variations in stratification become sufficiently large at equilibrium to reduce the degree of compensation along the midocean ridge flanks. The resulting large net transformations are similar to estimates for the abyssal ocean and span the vertical extent of the ridge. These results suggest that boundary flows generated by mixing play a crucial role in setting the global ocean stratification and overturning circulation, requiring a revision of abyssal ocean theories.
\end{abstract}

\section{Motivation}

The abyssal ocean, below $2500 \mathrm{~m}$, is a massive reservoir for climatically active tracers such as carbon and heat. The rates at which heat is mixed and advected into the high-capacity abyssal ocean are key parameters in understanding both past climate reconstructions (e.g., Toggweiler et al. 1989) and future projections of climate change (e.g., Hansen et al. 1985). Similarly, the partitioning of carbon between the deep ocean and the atmosphere is a major factor on millennial-scale climate change, whether natural (e.g., Sarmiento and Toggweiler 1984) or anthropogenic in origin (Archer et al. 1998). It is thus vital to have a firm phenomenological and dynamical understanding of the abyssal ocean's mean state.

The general structure of the abyssal ocean circulation is easily inferred from surface buoyancy fluxes and

Corresponding author: Henri F. Drake, henrifdrake@gmail.com large-scale tracer properties (Sverdrup et al. 1942). Antarctic Bottom Waters, the densest oceanic waters, form in the Southern Ocean and fill the global abyssal oceans up to a depth of about 2500 m (Talley 2013a). They outcrop at the surface only in the Southern Ocean, where they experience a significant area-integrated buoyancy loss (Abernathey et al. 2016) and are converted back into lighter waters by mixing with lighter overlying waters, resulting in a diabatic abyssal overturning circulation of $O(15) \mathrm{Sv}$, where $1 \mathrm{~Sv} \equiv 10^{6} \mathrm{~m}^{3} \mathrm{~s}^{-1}$. Nonlinearities in the equation of state of seawater and geothermal heating at the seafloor are thought to play secondary roles in shaping this circulation (Emile-Geay and Madec 2009; de Lavergne et al. 2016a) and will be ignored in the conceptual models described below.

Classical theories for the abyssal ocean describe the steady state circulation and stratification of a flat-bottom ocean forced by uniform turbulent mixing (Stommel 1957; Robinson and Stommel 1959; Stommel and Arons 1959a,b; 
Munk 1966). These theories remain pedagogically useful, but are at best qualitative descriptions, as demonstrated for example by the fact that the direction of the flow in the Stommel and Arons (1959a) solution changes sign when a sloping seafloor is introduced (Rhines 1993) and that the Munk (1966) solution does not satisfy the no-flux boundary condition at the seafloor. The classical view of a uniform mixing-driven upwelling is further challenged by the observation that turbulent mixing is typically bottom-enhanced over rough topography [see MacKinnon et al. (2017) for a recent review], reversing the sign of the vertical flow implied by the interior ocean vertical density balance (Polzin et al. 1997; Ferrari et al. 2016).

Since Munk (1966), several approaches have been taken to address the limitations of classical theories. First, boundary layer theories (Wunsch 1970; Thorpe 1987; Garrett 1990; Thompson and Johnson 1996) arose to elucidate the local behavior of mixing-induced flow along a sloping and insulating sea floor. Second, the limitations of the Stommel and Arons (1959a) theory inspired a number of extensions to account for baroclinic structure (Kawase 1987; Pedlosky 1992), nonuniform seafloor depth (Rhines 1993), and/or nonuniform turbulent diffusivities $\kappa$ (Marotzke 1997; Samelson 1998). Third, the observation of bottom-enhanced mixing motivated the development of progressively more sophisticated parameterizations of vertical (or diapycnal) turbulent diffusivities (Bryan and Lewis 1979; St. Laurent and Garrett 2002; Polzin 2009) which have been subsequently implemented into general circulation models (Huang and Jin 2002; Jayne 2009; Melet et al. 2016). Fourth, the conundrum of interior downwelling implied by bottom-enhanced mixing was resolved by applying the water mass transformation framework to a downwelling interior layer of turbulent buoyancy flux divergence and an upwelling bottom boundary layer of turbulent buoyancy flux convergence, respectively (Ferrari et al. 2016; de Lavergne et al. 2016b; McDougall and Ferrari 2017). Despite the direct relevance of all of these approaches to the abyssal circulation, there has been little work done to unify them into a general theory of the abyssal circulation and stratification.

Building on the framework introduced by Callies and Ferrari (2018, hereafter CF18), we present a unified prognostic model of the circulation in an abyssal basin forced by bottom-enhanced mixing along a midocean ridge. We modify the geometry, buoyancy forcing, and initial condition of the CF18 model to include the effects of a smooth midocean ridge (with the effects of local roughness parameterized by bottom-enhanced mixing) and of a nonuniform background stratification on the circulation. Our approach is to formulate the simplest possible model which captures what we believe to be the key aspects of the problem: 1) the transformation of abyssal bottom waters into relatively lighter deep waters by bottom-enhanced mixing on the flanks of a midocean ridge, 2) frictional processes acting on boundary currents, 3) restratification of abyssal mixing layers by baroclinic turbulence (crudely parameterized as a linear drag on the horizontal flow), and 4) bottom water formation in the Southern Ocean.

The general structure of the abyssal circulation that emerges from the model consists of layered deep western boundary currents (DWBCs) along the western continental slope which are connected by zonal flows to water mass transformations driven by bottom-enhanced mixing along a midocean ridge, as schematized in Fig. 1. The evolution of the interior stratification and the mixing layer water mass transformations are coupled by slope-normal exchange flows, with the vertically varying equilibrium stratification being determined by a combination of the mixing layer dynamics and the formation of dense waters in the south. Finite net water mass transformations arise ubiquitously along the flanks of the midocean ridge, supported by vertical variations in the interior stratification, such that the crest of the midocean ridge determines the vertical extent of the abyssal overturning cell, in contrast to a previous constant-stratification interpretation in which finite net transformations are confined to the base of topographic slopes (CF18).

The paper is structured as follows. Section 2 reviews the results of several theories of abyssal stratification and circulation in the literature. Section 3 presents the formulation of the planetary geostrophic circulation model (PGCM) used to produce the simulation results presented in the paper. Section 4 describes the general structure of the abyssal circulation as it emerges in the PGCM. In section 5 we use local solutions to the one-dimensional boundary layer equations to emulate the three-dimensional abyssal circulation in the PGCM. Section 6 describes the spinup to equilibrium of the vertical structure of abyssal interior stratification and its influence on water mass transformations. Section 7 compares water mass transformations in our PGCM simulations with estimates for the midocean ridges of the Pacific, Atlantic, and Indian Ocean basins. Section 8 compares diagnostic estimates of abyssal upwelling from the water mass transformation framework with the classic vertical advection-diffusion framework and evaluates the relative contributions of various physical terms of the water mass transformation. Section 9 discusses the implications of our results, some key caveats, and some promising future directions. 


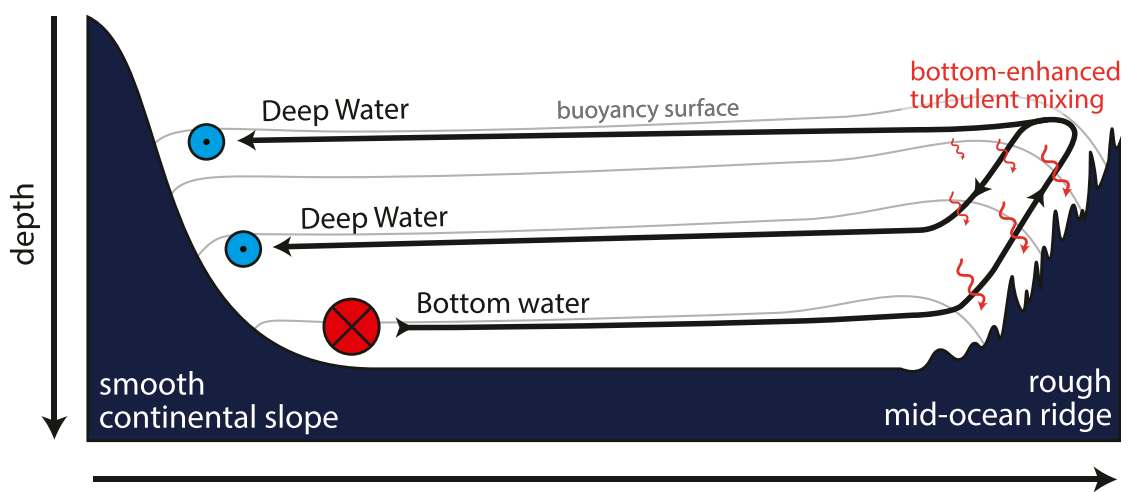

longitude / zonal distance

FIG. 1. Schematic of a basin-scale abyssal circulation driven by near-boundary mixing. Dense bottom waters flow northward out of the Southern Ocean via a DWBC (red circle) along the smooth and relatively quiescent continental slope, where little water mass transformation occurs. A cross-basin zonal flow feeds bottom waters from the DWBC into a system of abyssal mixing layers driven by bottom-enhanced turbulent mixing over the rough topography of the midocean ridge flanks (squiggly orange arrows). The turbulent buoyancy flux converges in a BBL, driving vigorous diabatic upwelling across buoyancy surfaces (gray lines). In an SML above, the buoyancy flux diverges, driving diabatic downwelling. The net effect of the up- and downwelling in the abyssal mixing layers is a net transformation of bottom waters into deep waters. The newly formed deep waters return via cross-basin zonal flows to the smooth continental slope, wherein they flow southward in a DWBC (blue circles) to close the abyssal circulation in the Southern Ocean. For simplicity, we omit the alternating along-ridge flows (see Fig. 3b) that are in frictional thermal wind balance with the plunging isopycnals.

\section{Theoretical background}

\section{a. Classical theories of abyssal stratification and circulation}

Modern theories of the abyssal circulation begin with a series of papers by Stommel and Arons (1959a,b). In their theory, the circulation of a homogeneous abyssal layer is fed by high-latitude sources of abyssal water (diabatic downwelling) and driven by a uniformly distributed sink (diabatic upwelling) of abyssal water. A uniform upwelling across the base of the thermocline is prescribed, inspired by the thermocline-thermohaline theory of Robinson and Stommel (1959). Munk (1966) further simplifies the Robinson and Stommel (1959) balance by restricting his attention to the deep ocean (i.e., below the thermocline) and by considering only vertical advection and diffusion,

$$
u^{z} \partial_{z} b=\partial_{z}\left(\kappa \partial_{z} b\right)
$$

where $b$ is buoyancy, $u^{z}$ is a uniform vertical velocity, and $\kappa$ is a uniform turbulent diffusivity. The Munk formulation allows exponential solutions that can be fit to the observed temperature profiles and combined with fits of an advection-diffusion-decay equation to radiocarbon profiles to yield the canonical estimate of deep ocean mixing $\kappa \simeq 10^{-4} \mathrm{~m}^{2} \mathrm{~s}^{-1}$ for a uniform upwelling of $u^{z}=1.4 \times 10^{-7} \mathrm{~m} \mathrm{~s}^{-1}$.
The horizontal abyssal circulation associated with the upwelling is described by Stommel and Arons (1959a,b): interior flow is geostrophically balanced and its meridional component $u^{y}$ is driven by vortex stretching, as shown by the vertically integrated planetarygeostrophic vorticity balance

$$
\beta U^{y}=f \frac{u_{0}^{z}}{H},
$$

where $H$ is the thickness of the abyssal layer, $u_{0}^{z}>0$ is the upwelling across the base of the thermocline, $f$ is the Coriolis parameter, $\beta>0$ is the meridional gradient of the Coriolis parameter, and the vertically integrated flow $U^{y}$ is thus poleward in both hemispheres (see Pedlosky 1996 for an elucidating derivation). Inspired by the success of analogous theories for the wind-driven gyre circulation (Stommel 1948), Stommel and Arons (1959a,b) suppose the existence of a deep western boundary current in which frictional effects allow the current to deviate from geostrophy and return the interior flow such that the abyss conserves mass.

\section{b. Turning ocean mixing upside down}

The Stommel and Arons (1959a,b) and Munk (1966) theories rely on the existence of a uniform turbulent diffusivity $\kappa \simeq 10^{-4} \mathrm{~m}^{2} \mathrm{~s}^{-1}$, roughly an order of magnitude larger than the interior ocean mixing inferred from 
observations (Gregg 1989; Ledwell et al. 1993). While sufficiently vigorous mixing was eventually discovered deeper in the ocean near rough seafloor topography (Polzin et al. 1997; Ledwell et al. 2000; Sheen et al. 2013), the abyssal mixing problem only became more complicated: applying the vertical advection-diffusion balance [Eq. (1)] pointwise to mixing profiles $\kappa(z) \partial_{z} b$ that increase with depth implies diapycnal downwelling

$$
u^{z}=\left(\partial_{z} b\right)^{-1} \partial_{z}\left(\kappa \partial_{z} b\right)<0,
$$

in contrast to the diapycnal upwelling required to balance diapycnal downwelling at high latitudes! ${ }^{1}$

This apparent conundrum is resolved by considering the insulating boundary condition at a sloping seafloor, which causes buoyancy convergence and hence diapycnal upwelling in a thin bottom boundary layer (Polzin et al. 1997; Ferrari et al. 2016; de Lavergne et al. 2016b). In this framework, the abyssal overturning is the net effect of downwelling driven by bottomenhanced mixing in a stratified mixing layer and upwelling driven by buoyancy convergence in a bottom boundary layer, which we collectively refer to as abyssal mixing layers (CF18).

\section{c. A puzzling constraint from boundary layer theory}

Bottom boundary layer theory [see review of Garrett et al. (1993)] is a useful dynamical approach to the problem of flow driven by near-boundary mixing on a slope, which exerts a strong control on the basin-scale abyssal circulation (CF18). Following Thorpe (1987), who built on the approaches of Wunsch (1970) and Phillips (1970), we rotate the Boussinesq equations into slope coordinates and assume the flow depends only on the slope-normal coordinate $z^{\prime}$, which gives the simplified buoyancy equation (see derivation of full equation set in section 5a):

$$
\partial_{t} b^{\prime}+u^{x^{\prime}} N_{0}^{2} \sin \theta=\partial_{z^{\prime}}\left[\kappa\left(N_{0}^{2} \cos \theta+\partial_{z^{\prime}} b^{\prime}\right)\right]
$$

where $u^{x^{\prime}}$ is the upslope velocity, $\theta$ the slope angle, $\kappa=$ $\kappa\left(z^{\prime}\right)$ the turbulent diffusivity, and we decompose the buoyancy field $b(x, y, z, t)=N_{0}^{2} z+b^{\prime}(x, y, z, t)$ into a background corresponding to a constant stratification $N_{0}^{2}$ and a buoyancy anomaly $b^{\prime}=b^{\prime}\left(z^{\prime}, t\right)$. The boundary conditions are a no-flux condition $\partial_{z^{\prime}} b=\partial_{z^{\prime}} b^{\prime}+N_{0}^{2} \cos \theta=0$ at the seafloor $z^{\prime}=0$ and decay conditions $\partial_{z^{\prime}} u^{x^{\prime}}$, $\partial_{z^{\prime}} b^{\prime} \rightarrow 0$ as $z^{\prime} \rightarrow \infty$. At steady state, the boundary layer

\footnotetext{
${ }^{1}$ While the sign of the vertical velocity changes, we note that $\partial_{z} u^{z}>0$ and thus the interior geostrophic flow driven by vortex stretching is still of the same sign as in the Stommel-Arons solution.
}

equation for the buoyancy anomaly [Eq. (4)] can be integrated from $z^{\prime}=0$ to $z^{\prime} \rightarrow \infty$, which yields

$$
\Psi_{\mathrm{bg}} \equiv \kappa_{\mathrm{bg}} \cot \theta
$$

for the net upslope transport per unit length $\Psi_{\text {bg }}=$ $\int_{0}^{\infty} u^{x^{\prime}} d z^{\prime}$, where $\kappa_{\mathrm{bg}} \equiv \kappa(z \rightarrow \infty)$ is the background diffusivity. The simplicity of this integral constraint is surprising: the net upslope transport depends only on the background turbulent diffusivity $\kappa_{\mathrm{bg}}$ and the slope angle $\theta$, and is independent of other environmental parameters which might be expected to influence diapycnal transport, such as frictional parameters, the background stratification $N_{0}^{2}$, the Coriolis parameter $f$, and the vertical structure of the turbulent diffusivity $\kappa(z)$.

Integrating the prediction $\Psi_{\mathrm{bg}}$ for the diapycnal transport per unit length along the perimeter $L_{\text {global }} \simeq$ $10^{8} \mathrm{~m}$ of the global midocean ridge system (Callies 2018) for a typical ridge slope $\tan (\theta)=2 \times 10^{-3}$ and a background diffusivity of $\kappa_{\mathrm{bg}} \simeq 10^{-5} \mathrm{~m}^{2} \mathrm{~s}^{-1}$ produces a global mixing-driven diapycnal overturning transport of $L_{\text {global }} \kappa_{\mathrm{bg}} \cot \theta \simeq 0.5 \mathrm{~Sv}$, more than an order of magnitude smaller than the observed abyssal diapycnal overturning transport of roughly $15 \mathrm{~Sv}$ (Lumpkin and Speer 2007).

CF18 resolve this conundrum by using the magnitude of the upwelling-downwelling "dipole" from boundary layer theory as a prediction for the net water mass transformation, since at the base of topographic slopes the flows in and out of the boundary layers occur at different density classes and thus drive a diabatic overturning. They find that the strictly upwelling transport in the bottom boundary layer accurately predicts the scaling of the maximum net diapycnal overturning transport, although the predicted overturning is unrealistically confined to the base of topographic slopes, where the constraints from one-dimensional boundary layer theory break down.

\section{d. Boundary-interior exchange}

The integral constraint $\Psi_{\mathrm{bg}} \equiv \kappa_{\mathrm{bg}} \cot \theta$ [Eq. (5)] relies on the assumption of constant background stratification $N_{0}^{2}$ and slope angle $\theta$. By construction, none of the other terms are assumed to vary in the plane of the slope $\left(x^{\prime}, y^{\prime}\right)$ either; it follows that there are no crossslope convergences $\partial_{x^{\prime}} u^{x^{\prime}}=0$ and hence no slope-normal exchange between the abyssal mixing layers and the interior, $u^{z^{\prime}}=0$ (Wunsch 1970).

With a vertically varying stratification $N^{2}(z)$, however, variations in the buoyancy gradient project onto the cross-slope direction $x^{\prime}=x \cos \theta+z \sin \theta$, introducing a second dimension to the problem (e.g., Phillips et al.1986; Salmun et al. 1991) and permitting both slope-normal 
exchange flows $u^{z^{\prime}} \neq 0$ and a net diapycnal transport $\Psi_{\infty} \equiv \int_{0}^{\infty} u^{x^{\prime}} d z^{\prime} \neq \Psi_{\mathrm{bg}}$. Heterogeneities can also arise due to cross-slope variations in the turbulent diffusivity $\kappa(x, y)$ or the slope angle $\theta(x, y)$ (Dell and Pratt 2015), and have been argued to contribute significantly to oceanic water mass transformations (McDougall and Ferrari 2017; de Lavergne et al. 2017; Holmes et al. 2018). These additional heterogeneities are both kept relatively small by construction in our idealized model configuration to keep the focus on the effects of variations in the basin stratification.

\section{e. Dynamics controlling the interior abyssal stratification}

The abyssal stratification is thought to be controlled by the combined effects of 1) diapycnal mixing in ocean basins and 2) the competing effects of winds and mesoscale eddies in setting the slope of isopycnals in the Southern Ocean. Diapycnal mixing maintains the stable stratification of the abyssal ocean by effectively diffusing buoyancy downward, transforming dense abyssal waters into lighter deep waters (Munk 1966). This vertical advection-diffusion model is an incomplete model of the abyssal stratification, however, as it omits the complementary process that closes the overturning circulation by transforming light deep waters into denser abyssal waters. Munk and Wunsch (1998) consider a heuristic correction to Munk's (1966) vertical advection-diffusion equation for the effect of horizontal advection from regions of high mixing (or homogenization by convection), which acts to restratify regions of weak mixing. A breakthrough in understanding the abyssal stratification was the development of quasi-adiabatic theories of Southern Ocean circulation. In these theories, deep waters are upwelled adiabatically along sloping isopycnals in the Southern Ocean, are transformed into abyssal waters in the Southern Ocean mixed layer by a negative surface buoyancy flux, and return to the abyss adiabatically along isopycnals (Marshall and Speer 2012, and references therein). The Southern Ocean isopycnal slope is determined by a balance between wind stress and stirring by mesoscale eddies, which steepen and flatten isopycnals, respectively (Marshall and Radko 2003).

Building on these two independent theories, Nikurashin and Vallis (2011) develop an idealized model which couples quasi-adiabatic Southern Ocean dynamics to a diabatic abyssal ocean basin and predicts the abyssal stratification and circulation, given only surface boundary conditions and mixing coefficients. For moderate diapycnal mixing of $10^{-5} \mathrm{~m}^{2} \mathrm{~s}^{-1}<\kappa<10^{-3} \mathrm{~m}^{2} \mathrm{~s}^{-1}$, a regime applicable to both the Ocean and the model described here, the Nikurashin and Vallis (2011) model predicts that the interior abyssal stratification depends both on winds and eddies in the Southern Ocean and diapycnal mixing in the basin.

A promising aspect of zonally integrated models of the meridional overturning circulation (e.g., Nikurashin et al. 2012; Thompson et al. 2016) is that they accurately reproduce the overturning and stratification exhibited by idealized "box"-geometry general circulation models. The emerging view, however, is that the abyssal circulation of the ocean is controlled by mixing layer flows along sloping boundaries and thus that the commonly used "box" geometry models may be a misleading point of reference for theories of the abyssal stratification and circulation (Ferrari et al. 2016). Building on CF18, we describe the formulation of an improved idealized general circulation model in a "bowl + ridge" geometry which accommodates the recent revisions to our theoretical understanding of the abyssal ocean circulation.

\section{Planetary geostrophic circulation model (PGCM)}

The numerical model used here is the planetary geostrophic circulation model (PGCM) developed by CF18 to study how bottom-enhanced mixing on slopes drives an abyssal circulation. We describe the key elements of our PGCM configuration below, which closely follows the exposition of CF18. The main differences between the present study and CF18 are the inclusion of the midocean ridge, the localization of vigorous bottom-enhanced mixing to a midocean ridge, and the generalization to vertically varying interior stratifications. Readers familiar with the methods of CF18 can skip section 3 and simply consult Fig. 2, which summarizes our changes to the configuration.

\section{a. Equations}

The model solves the Navier-Stokes equations under the Boussinesq and planetary-scale geostrophic approximations, with parameterizations for the frictional and diabatic effects of unresolved processes, given by

$$
\begin{aligned}
f \mathbf{z} \times \mathbf{u} & =-\nabla p+b \mathbf{z}-r\left(u^{x} \mathbf{x}+u^{y} \mathbf{y}\right), \\
\nabla \cdot \mathbf{u} & =0, \quad \text { and } \\
\frac{\partial b}{\partial t}+\mathbf{u} \cdot \nabla b & =\nabla \cdot(\kappa \nabla b)-\lambda(y)[b-B(z)],
\end{aligned}
$$

where $t$ is time; $\mathbf{x}, \mathbf{y}, \mathbf{z}$ are unit vectors pointing east, north, and up, respectively; $f=\beta y$ is the linearized Coriolis parameter ( $\beta$-plane approximation); $\mathbf{u}=\left(u^{x}\right.$, $\left.u^{y}, u^{z}\right)$ is the velocity vector; $p$ is the pressure divided 

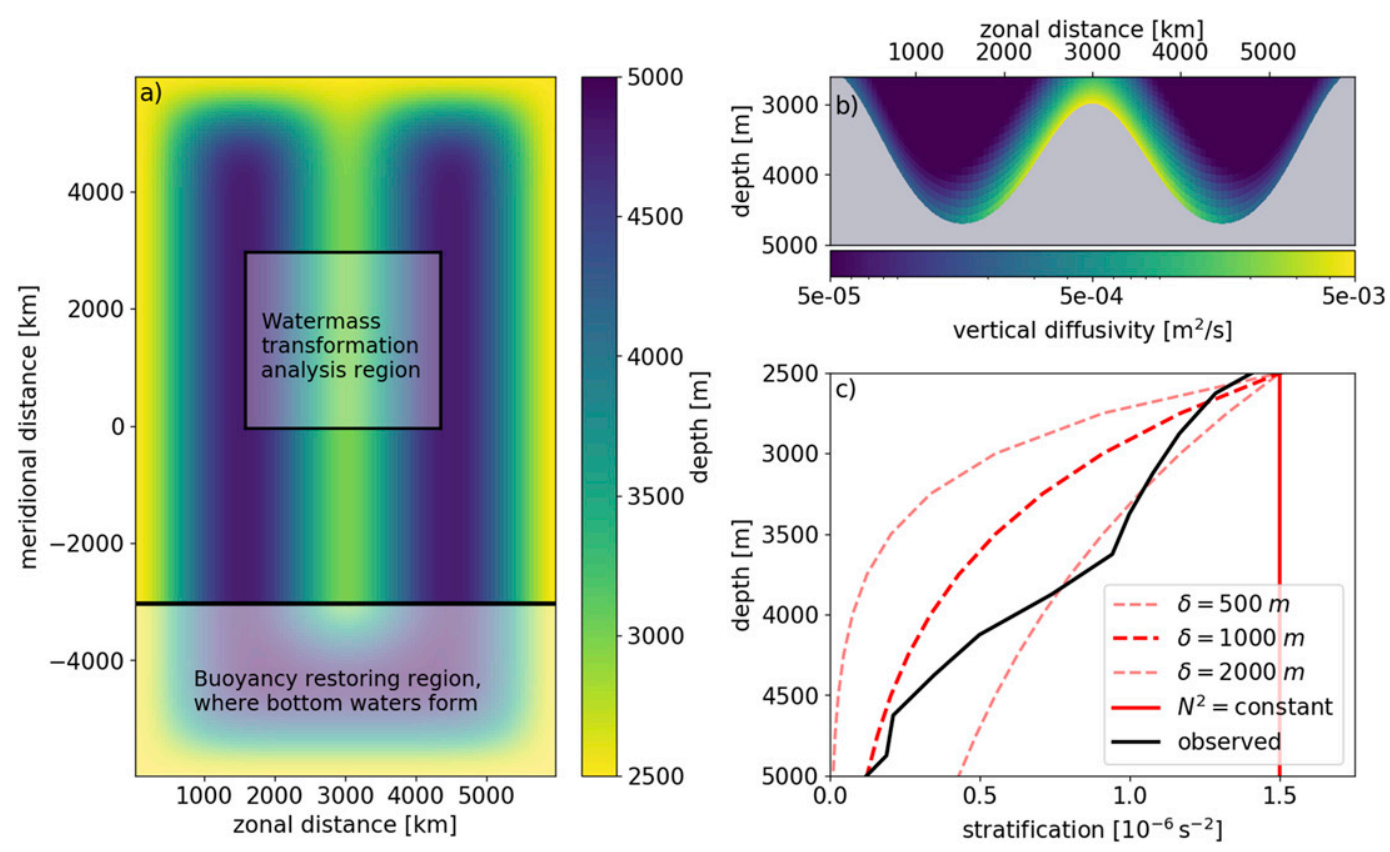

FIG. 2. Configuration of the PGCM. (a) Seafloor depth in the PGCM. We highlight the southern restoring region where we apply a buoyancy restoring which acts to transform deep waters into bottom waters (see section 3c) and a Northern Hemisphere region in which we diagnose water mass transformations along the midocean ridge (see section 4c). (b) Zonal section of the imposed turbulent diffusivity $\kappa$, which is bottom-enhanced over the midocean ridge. (c) The red lines show the four stratification profiles $B_{z}$ used in the PGCM as both the initial condition and as the reference profile for buoyancy restoring in the southern restoring region. The black line shows the observed stratification profile from the World Ocean Circulation Experiment (Gouretski and Koltermann 2004) in the South Pacific, averaged horizontally from $55^{\circ}$ to $45^{\circ} \mathrm{S}$ and from $175^{\circ} \mathrm{E}$ to $115^{\circ} \mathrm{W}$.

by a reference density; $b$ is the buoyancy; $r$ is a frictional parameter; $\kappa=\kappa(x, y, z)$ is a spatially dependent turbulent diffusivity; and $\lambda=\lambda(y)$ is a meridionally varying restoring rate (see section $3 \mathrm{c}$ ). The system of equations (6)-(8), with appropriate initial and boundary conditions, yields a self-consistent and prognostic model of abyssal circulation and stratification.

The Boussinesq approximation filters out acoustic waves while the planetary geostrophic approximation filters out gravity waves and geostrophic turbulence. The resulting planetary geostrophic equations are appropriate for basin-scale oceanic circulations and are typically used for idealized studies of the abyssal circulation (e.g., Pedlosky 1996, and references therein) and intermediate-complexity Earth system models (e.g., Holden et al. 2016). While it is computationally and conceptually useful that the planetary geostrophic equations filter out the effects of fast waves and turbulence, the turbulent fluxes of these relatively small-scale flows are thought to have leading-order effects on abyssal mixing layers. We include their qualitative effects in the planetary geostrophic formulation by way of two idealized parameterizations.
First, to include the effects of turbulent mixing produced by the local breaking of internal waves generated by flow over rough topography, we introduce a term for the turbulent buoyancy flux convergence $\nabla \cdot(\kappa \nabla b)$ to the buoyancy equation (e.g., as in St. Laurent and Garrett 2002). The imposed spatially dependent turbulent diffusivity $\kappa(x, y, z)$ approximates the leading-order spatial structure described by observational estimates ${ }^{2}$ (e.g., Polzin et al. 1997; Waterhouse et al. 2014) and is described in detail in section 3c.

Second, to include the qualitative effects of isopycnal mixing by baroclinic turbulence in restratifying the abyssal mixing layers (Callies 2018) and in thickening western boundary currents (e.g., Stommel 1948), we introduce a dissipative term to the momentum equation. Greatbatch and Lamb (1990) show that introducing vertical momentum diffusion $\partial_{z}\left(\nu_{\text {eddy }} \partial_{z} \mathbf{u}\right)$ to the

\footnotetext{
${ }^{2}$ Quantitatively similar profiles of turbulent kinetic energy dissipation are reproduced in simulations of internal wave turbulence above rough topography, wherein energy from a geostrophic mean flow (Nikurashin and Ferrari 2010) or the barotropic tide (Nikurashin and Legg 2011) is converted into unstable high-mode internal waves via a cascade of wave-wave interactions.
} 
planetary geostrophic equations with an eddy viscosity $\nu_{\text {eddy }}=\kappa_{\mathrm{GM}} f^{2} / N^{2}$ is equivalent to introducing isopycnal diffusion of potential vorticity with an effective isopycnal diffusivity of $\kappa_{\mathrm{GM}}$ (Gent and McWilliams 1990). Following Salmon (1992), we simplify the dynamics further by using a linear friction term (Rayleigh drag) $-r\left(u^{x} \mathbf{x}+u^{y} \mathbf{y}\right)$ and scale the frictional parameter $r$ according to the Greatbatch and Lamb (1990) parameterization,

$$
r=\kappa_{\mathrm{GM}} \frac{f^{2}}{\delta^{2} N^{2}} \approx 1.2 \times 10^{-5} \mathrm{~s}^{-1},
$$

where we choose $\delta=400 \mathrm{~m}$ to be roughly the thickness of the abyssal mixing layers observed in the Brazil Basin (Callies 2018); typical abyssal mixing layer values of $f=$ $5 \times 10^{-5} \mathrm{~s}$ and $N^{2}=5 \times 10^{-7} \mathrm{~s}^{-1}$; and in the absence of observational or theoretical constraints assume $\kappa_{\mathrm{GM}}=$ $100 \mathrm{~m}^{2} \mathrm{~s}^{-1}$, which yields a value $\nu_{\text {eddy }}=0.5 \mathrm{~m}^{2} \mathrm{~s}^{-1}$ similar to the value $\nu_{\text {eddy }}=\sigma \kappa_{\text {bot }}=0.4 \mathrm{~m}^{2} \mathrm{~s}^{-1}$ proposed by Callies (2018) and Holmes et al. (2019), where $\sigma$ is the turbulent Prandtl number. We use a constant $r$ since the parameterization is meant to be a crude placeholder for boundary layer restratification. To our relief, supplementary sensitivity experiments showed that water mass transformations and the boundary layer structure are relatively insensitive to the friction parameter $r$, in agreement with CF18. The linear drag parameter is small enough that the frictional terms are negligible in the interior where the flow is approximately geostrophic and are important only in near-boundary flows (both the DWBCs and the abyssal mixing layers along the midocean ridge) where the horizontal velocities are large (Salmon 1992; CF18). The choice of $r=1.2 \times 10^{-5} \mathrm{~s}^{-1}$ gives a nondimensional value $\hat{r}=(r / \beta L)=0.1$ such that the width of the Stommel and Arons (1959a,b) DWBCs is one-tenth the domain width (see section $3 \mathrm{~d}$ ).

\section{b. Geometry and boundary conditions}

We configure the PGCM to approximate the leadingorder structure of a typical cross-hemispheric abyssal ocean basin with a rectangular basin of zonal width $L=$ $3000 \mathrm{~km}$ and meridional length $2 L=6000 \mathrm{~km}$. Our idealized basin contains a midocean ridge caused by seafloor spreading in the middle and is bounded in the west, east, and north by continental slopes (Fig. 2a). Although the southern region in our configuration $[y<-(L / 2)=-3000 \mathrm{~km}]$ is also zonally bounded, it should be thought of as a Southern Ocean-like sponge layer. In this southern region, the transformation of deep waters into bottom waters arising from complex circumpolar channel dynamics (e.g., as described in Marshall and Speer 2012) are parameterized by an idealized buoyancy restoring forcing which pins the buoyancy field to a reference vertical profile (described in detail in the next section 3c). The model extends from $z=-2500 \mathrm{~m}$ at the upper boundary to a maximum depth of $z=-5000 \mathrm{~m}$ and should be interpreted as representing only the diabatic lower cell of the meridional overturning circulation. The idealized configuration can be thought to apply locally to the Atlantic, Pacific, and Indian Ocean basins below $z=-2500 \mathrm{~m}$, which in the present climate are all bounded by topography in the west, east, and north and have roughly meridionally aligned midocean ridges (e.g., those highlighted in Fig. 12). The idealized continental slopes are half-Gaussian and the midocean ridge is Gaussian in the zonal direction and tapers down to zero meridionally in the southern restoring region to allow unconstrained zonal flows to close the circulation of interest in the diffusively forced basin to the north. The characteristic seafloor slopes of roughly $\tan \left(\theta_{\text {ridge }}\right) \simeq 2 \times 10^{-3}$ for the midocean ridge and $\tan \left(\theta_{\text {cont. }}\right) \simeq 4 \times 10^{-3}$ for the continental slope are inspired by the South Atlantic, where the abyssal mixing layers and large-scale abyssal circulation are best constrained by existing observations (Hogg et al. 1982; Polzin et al. 1997; Ledwell et al. 2000; St. Laurent et al. 2001; Thurnherr et al. 2005). The PGCM is bounded from above by assuming isopycnals are flat, i.e., $b=0$ at $z=-2500 \mathrm{~m}$, which is approximately valid in all basins north of the Southern Ocean (Talley 2007; Koltermann et al. 2011; Talley 2013b). The PGCM is bounded from below by an insulating seafloor, $\mathbf{n} \cdot \nabla b=0$ at $z=-d(x, y)$, where $d(x, y)$ is the seafloor depth and $\mathbf{n}$ is the unit vector normal to the boundary.

\section{c. Buoyancy forcing}

The abyssal circulation in our model is forced by two competing diabatic terms in the buoyancy equation: minus the divergence of the turbulent buoyancy flux $-\nabla \cdot(-\kappa \nabla b)$, which has a positive integral contribution (diapycnal upwelling); and restoring to a reference buoyancy profile $-\lambda(b-B)$, which must necessarily have a negative integral contribution (diapycnal downwelling). Available potential energy is produced by parameterized turbulent mixing and converted into kinetic energy via the buoyancy production term $u^{z} b$ to drive a planetary geostrophic abyssal circulation and balance the available potential energy loss due to restoring.

\section{1) Turbulent MiXING}

The prescribed turbulent diffusivity $\kappa=\kappa(x, y, z)$ is everywhere bottom-enhanced with a contribution equal to $\kappa_{\text {bot }} \exp [-(z+d) / h]$ over the midocean 
ridge, where we choose $\kappa_{\text {bot }}=5 \times 10^{-3} \mathrm{~m}^{2} \mathrm{~s}^{-1}$ and $h=$ $250 \mathrm{~m}$ to roughly match observations in the Brazil Basin (Fig. 11). The bottom-enhanced contribution to $\kappa$ is reduced by a factor of 20 to $\left(\kappa_{\text {bot }} / 20\right) \exp [-(z+d) / h]$ over the continental slopes to reflect the observed weakness of local wave-driven turbulence over smooth continental slopes (Fig. 11 and Polzin et al. 1997). A uniform weak background diffusivity $\kappa_{\text {bg }}=\left(\kappa_{\text {bot }} / 200\right)=$ $2.5 \times 10^{-5} \mathrm{~m}^{2} \mathrm{~s}^{-1}$ is added to stabilize the numerical solution, yielding a total diffusivity distribution

$$
\kappa(x, y, z)=\kappa_{\mathrm{bg}}+ \begin{cases}\kappa_{\mathrm{bot}} \exp \{-[z+d(x, y)] / h\}, & \text { if } L / 2<x<3 L / 2 \text { (midocean ridge) } \\ \frac{\kappa_{\mathrm{bot}}}{20} \exp \{-[z+d(x, y)] / h\}, & \text { else (continental slopes) }\end{cases}
$$

with a smoothing function applied over a horizontal distance of $L / 10$ near the transitions at $x=L / 2$ and $x=$ $3 L / 2$. The net effect of this prescribed mixing is to power a diabatic upwelling along the midocean ridge, where mixing is vigorous.

\section{2) BUOYANCY RESTORING IN THE SOUTHERN RESTORING REGION}

The prescribed restoring rate $\lambda$ has a meridional dependence

$$
\lambda(y)=\lambda_{0}\left(0.5\left\{1-\tanh \left[\frac{y+(L / 2)}{10 L}\right]\right\}\right)
$$

which is equal to $\lambda_{0} \simeq(10 \text { years })^{-1}$ in the southern restoring region and vanishes rapidly northward, $\lambda \rightarrow 0$ as $y>-L / 2$. The prescribed restoring rate is chosen based on the baroclinic adjustment time scale given by a lateral diffusive time scale $\tau_{\mathrm{SO}}=L_{\mathrm{SO}}^{2} / \kappa_{\mathrm{GM}}=\left(10^{6} \mathrm{~m}\right)^{2} / 3000 \mathrm{~m}^{2} \mathrm{~s}^{-1} \simeq$ 10 years, determined for an isopycnal diffusivity $\kappa_{\mathrm{GM}} \simeq$ $3000 \mathrm{~m}^{2} \mathrm{~s}^{-1}$ (Abernathey et al. 2013) and a Southern Ocean of width $L_{\mathrm{SO}} \simeq 1000 \mathrm{~km}$. This restoring rate is much faster than the vertical diffusive time scale which spins up the overturning circulation $\tau_{\text {mix }}=H^{2} / \bar{\kappa} \simeq 1000$ years, where $H=2500 \mathrm{~m}$ is the maximum thickness of the abyssal ocean and $\bar{\kappa} \simeq 10^{-4} \mathrm{~m}^{2} \mathrm{~s}^{-1}$ is the volumeweighted mean diffusivity in the basin. Thus, the stratification in the southern restoring region does not deviate much from the prescribed profile (see Fig. 7). The net effect of this parameterized buoyancy forcing in the southern restoring region is to transform deep waters into bottom waters (diabatic downwelling) to balance the transformation of bottom waters into deep waters (diabatic upwelling) driven by mixing along the midocean ridge in the basin to the north. In contrast to CF18, we allow reference buoyancy profiles $B(z)$ corresponding to vertically varying stratification $\partial_{z} B=N^{2}(z)$, complicating the interpretation of the solution in terms of one-dimensional boundary layer dynamics which require a constant interior stratification $N_{0}^{2}$.

\section{d. Dimensional parameters and scaling}

While the PGCM is discussed in dimensional terms, the PGCM is formulated and implemented nondimensionally. The following dimensional scales,

$L=6000 \mathrm{~km} \quad$ (basin width),

$H=2500 \mathrm{~m} \quad$ (abyssal ocean vertical extent),

$\beta=2 \times 10^{-11} \mathrm{~m}^{-1} \mathrm{~s}^{-1}$

(meridional gradient of Coriolis parameter),

$N^{2}=1.5 \times 10^{-6} \mathrm{~s}^{-2}$

(reference stratification at $z=-2500 \mathrm{~m}$ ),

$\kappa_{\text {bot }}=5 \times 10^{-3} \mathrm{~m}^{2} \mathrm{~s}^{-1}$

(diffusivity at the midocean ridge seafloor),

$r=1.2 \times 10^{-5} \mathrm{~s}^{-1} \quad$ (frictional parameter)

are used to nondimensionalize the system, with the coordinate transformation

$$
x=L \hat{x}, \quad y=L \hat{y}, \quad z=H \hat{z}
$$

and the substitutions

$$
\begin{aligned}
t & =\frac{\beta L^{3}}{N^{2} H^{2}} \hat{t}, \quad b=N^{2} H \hat{b}, \quad p=N^{2} H^{2} \hat{p}, \\
u^{x} & =\frac{N^{2} H^{2}}{\beta L^{2}} \hat{u}^{\hat{x}}, \quad u^{y}=\frac{N^{2} H^{2}}{\beta L^{2}} \hat{u}^{\hat{y}}, \quad u^{z}=\frac{N^{2} H^{3}}{\beta L^{3}} \hat{u}^{\hat{z}} .
\end{aligned}
$$

For reference, the nondimensional time $\hat{t}=1$ corresponds to $t=\tau \simeq 10$ years, where $\tau \equiv\left(\beta L^{3} / N^{2} H^{2}\right)^{2}$. While the basin scale circulation takes a long time $\tau_{\text {mix }}=H^{2} / \bar{\kappa} \simeq$ 1000 years $\gg \tau$ to spin up, the abyssal mixing layers are spun up on a fast time scale $\tau_{\mathrm{BL}}=q^{-2} / \kappa_{\text {bot }} \simeq 1$ year $\ll \tau$, where

$$
q^{-1}=\sqrt{\frac{\kappa_{\mathrm{bot}}\left(f^{2}+r^{2}\right)}{r N^{2} \tan ^{2} \theta}} \simeq 400 \mathrm{~m}
$$


is the thickness of the mixing layer predicted by $1 \mathrm{D}$ theory (CF18), $\kappa_{\text {bot }}=5 \times 10^{-3} \mathrm{~m}^{2} \mathrm{~s}^{-1}$ is the diffusivity at the seafloor, and $f=\beta L / 2$ is a representative value of the Coriolis parameter.

The nondimensionalized equations (see CF18) depend only on the nondimensional parameters

$$
\hat{\alpha}=\frac{H}{L}, \quad \hat{\kappa}=\frac{\kappa \beta L^{3}}{N^{2} H^{4}}, \quad \hat{r}=\frac{r}{\beta L},
$$

where $\hat{\alpha}$ is the aspect ratio of the basin and $\hat{\kappa}=$ $(\kappa / \bar{\kappa}) \tau / \tau_{\text {mix }}$, where $\tau / \tau_{\text {mix }}$ is the ratio of the cross-basin propagation time scale of long Rossby waves (with $f=\beta L$ )

$$
\tau \equiv L / c_{g}=\left[L / \frac{\beta L^{-2}}{(N H / f)^{2}}\right]=\frac{\beta L^{3}}{N^{2} H^{2}},
$$

to the diffusive spinup time scale $\tau_{\text {mix }} \equiv H^{2} / \bar{\kappa}$. The term $\hat{r}$ is the ratio of the Stommel (1948) western boundary layer width $r / \beta$ to the basin width $L$. Since the prescribed $\kappa$ is spatially dependent, the nondimensional diffusivity $\hat{\kappa}$ inherits its spatial dependence $\kappa / \bar{\kappa}$. Scaling $\kappa$ by using the volume-weighted average value $\bar{\kappa}$ in $\tau_{\text {mix }}$ gives $\hat{\kappa}=\tau / \tau_{\text {mix }} \simeq 0.01$. Because the imposed turbulent diffusivity is isotropic, the small aspect ratio $\hat{\alpha} \sim 5 \times 10^{-4}$ results in a nondimensionalized horizontal diffusivity many orders of magnitude smaller than the nondimensionalized vertical diffusivity, which is difficult to implement numerically. Instead, we artificially increase the horizontal diffusivity for numerical stability by increasing the aspect ratio parameter to $\hat{\alpha}=0.2$. This parameter only enters in the horizontal diffusion term $\hat{\alpha}^{2}\left[\partial_{\hat{x}}\left(\hat{\kappa} \partial_{\hat{x}} \hat{b}\right)+\partial_{\hat{y}}\left(\hat{\kappa} \partial_{\hat{y}} \hat{b}\right)\right]$ (CF18) and remains small enough that it does not qualitatively affect the results presented here, as evidenced by the negligible role of horizontal buoyancy fluxes in the water mass transformations (Fig. 5).

\section{e. Numerical implementation}

The model is formulated in terrain-following coordinates to accurately resolve the thin mixing-driven flows along the sloped bottom boundary. The numerical implementation is described in CF18. The Julia (Bezanson et al. 2017) implementation is available at https:/github.com/ joernc/pgcm. The input files, output files, and postprocessing notebooks necessary to replicate the study are available at https://github.com/hdrake/AbyssalFlow (Drake 2020).

\section{Abyssal circulation controlled by mixing layer dynamics}

We begin by describing the general structure of the abyssal circulation at equilibrium in the PGCM, i.e., at $\hat{t}=50$ or $t \simeq 500$ years $\simeq \tau_{\text {mix }}$, when buoyancy tendencies have become sufficiently small (Fig. 7a). The stratification in the PGCM solution presented in this section is restored to an exponential profile with a decay scale of $\delta=1000 \mathrm{~m}$ in the southern region (solid red dashed line in Fig. 2), which exhibits vertical variations of similar magnitude to those observed in the Southern Ocean (black solid line). This is arguably our most "realistic" simulation of the abyssal ocean and hereafter we refer to it as PGCM-REAL.

\section{a. Abyssal mixing layers and DWBCs}

Figures 3a-c shows the three Cartesian components of the abyssal flow field along a zonal section $3000 \mathrm{~km}$ north of the equator. In the abyssal mixing layers spanning both flanks of the midocean ridge, buoyancy surfaces plunge to intersect the seafloor at a right angle (visually distorted by the aspect ratio) to satisfy the no-flux boundary condition. As expected from 1D theory (CF18), the boundary flows are thicker and stronger over the midocean ridge, where mixing is strong, than over the continental slopes, where mixing is weak. In the bottom boundary layer (BBL), plunging buoyancy surfaces drive frictionally balanced upwelling (Fig. 3c) and frictional-geostrophic flow opposite the direction of Kelvin wave propagation (Fig. 3b), i.e., anticyclonic in the Northern Hemisphere. In the stratified mixing layer (SML) just above the BBL, buoyancy surfaces are at leading-order flat and the bottomenhanced mixing drives downwelling (Fig. 3c), as expected from the vertical advection-diffusion balance [Eq. (3)] reviewed in section 2 .

Net diapycnal upwelling in the Northern Hemisphere can be inferred from the meridional flow field at the equator: dense bottom waters flow into the Northern Hemisphere and relatively lighter deep waters flow out (Fig. 3e). Since the Coriolis force vanishes at the equator, the buoyant force associated with the bending of buoyancy surfaces to satisfy the bottom-boundary condition can only be balanced by a cross-slope frictional flow (Figs. 3d,f) and any along-slope flows associated with the abyssal mixing layers vanish (cf. Fig. 3e to Fig. 3b). The only meridional flows are Stommel (1948)-like DWBCs along the continental slope on the western side of the domain and the eastern flank of the ridge (Fig. 3e). In this particular configuration, a southward-flowing DWBC develops on the eastern flank of the ridge near its crest and is much weaker than the DWBC on the western continental slope. The southward DWBC on the ridge is relatively intensified in simulations with a taller ridge.

\section{b. Depth-integrated and overturning circulations}

The global abyssal circulation is more intuitively visualized by considering the three Cartesian streamfunctions 

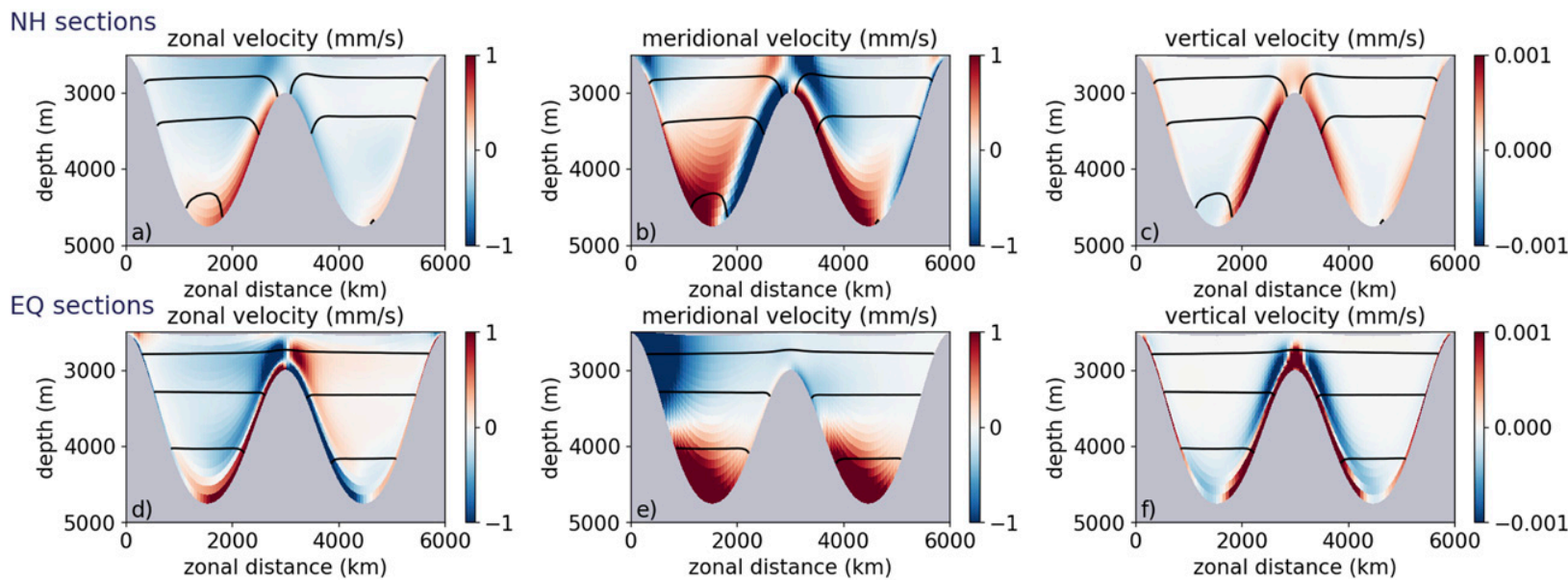

FIG. 3. Cartesian components of the velocity vector in the PGCM-REAL simulation along: (a)-(c) a midlatitude section in the Northern Hemisphere, $y=3000 \mathrm{~km}$, and (d)-(f) a section at the equator, $y=0 \mathrm{~km}$. Black lines show three equally spaced buoyancy surfaces.

that describe the flow, which we compute by integrating the velocities in $x, y$, and $z$, respectively ${ }^{3}$ (Fig. 4). Figure $4 \mathrm{~b}$ shows the familiar streamfunction for the meridional overturning circulation (MOC) in the $y-z$ plane, which should be thought of as corresponding to the lower cell of the global MOC. This circulation has a strength of about $1.6 \mathrm{~Sv}$ at the equator, with water 1) downwelling diabatically in the southern restoring region, 2) flowing northward to fill the abyssal depths, 3 ) gradually upwelling along the length of the basin, and 4) returning to the southern restoring region to close the circulation. We note in particular that the MOC extends all the way from the ocean seafloor to the top of the midocean ridge, in contrast to the MOC in the CF18 framework, in which significant overturning is confined to the base of topographic slopes (see section $6 \mathrm{c}$ for a discussion on the role of the ridge height in setting the vertical extent of the MOC).

The up- and downwelling in the abyssal mixing layers is evident in the zonal overturning streamfunction in the $x-z$ plane, which shows upwelling in a thin BBL and broader downwelling in the SML above (Fig. 4c). The upwelling in bottom boundary layers is confined to the two flanks of the midocean ridge, where mixing is vigorous and bottom enhanced, and is negligible over the weakly mixed continental slopes. In this case, the

\footnotetext{
${ }^{3}$ Integrating the continuity equation in $\left(\partial u^{x} / \partial x\right)+\left(\partial u^{y} / \partial y\right)+$ $\left(\partial u^{z} / \partial z\right)=0$ along any of the three directions $x, y$, or $z$ and imposing the no-normal flow boundary condition yields an equation of the form $\int\left[\left(\partial u^{x_{1}} / \partial x_{1}\right)+\left(\partial u^{x_{2}} / \partial x_{2}\right)+\left(\partial u^{x_{3}} / \partial x_{3}\right)\right] d x_{3}=\left(\partial U^{x_{1}} / \partial x_{1}\right)+$ $\left(\partial U^{x_{2}} / \partial x_{2}\right)=0$, where $x_{1}, x_{2}, x_{3}$ are permutations of $x, y, z$, $U^{x_{1}}=\int u^{x_{1}} d x_{3}$ and $U^{x_{2}}=\int u^{x_{2}} d x_{3}$. The resulting nondivergent flow field can then be expressed as a streamfunction $\psi_{3}$ defined by $\mathbf{U}=U^{x_{1}} \mathbf{x}_{1}+U^{x_{2}} \mathbf{x}_{2}=\left(-\nabla \times \psi_{3} \mathbf{x}_{3}\right)$.
}

upwelling and downwelling transports are equal and opposite in strength, i.e., the circulation closes, because the downwelling flow includes both the net diabatic upwelling along the ridge as well as the net diabatic downwelling by the restoring condition in the southern region, which is concentrated on the eastern continental slope. Nonetheless, the zonal overturning streamfunction provides a qualitative sense of the zonal overturning circulations driven by mixing layer dynamics along the midocean ridge.

The depth-integrated circulation in our simulations stands in contrast to that of Stommel and Arons's (1959b) barotropic model and is the expression of a combination of various baroclinic DWBCs and mixing layer flows (Fig. 4a). Within $2000 \mathrm{~km}$ of the equator, the northward and southward components of the DWBCs alternatively dominate (cf. with the meridional velocity at the equator in Fig. 3). North of $y=2000 \mathrm{~km}$, the depth-integrated circulation is dominated by the along-slope flow in the bottom boundary layer, which is opposite the direction of Kelvin wave propagation. The depth-integrated circulation is strongly influenced by mixing layer dynamics, both near the boundaries and in the interior, and is structurally distinct from that predicted by the linear response to vortex stretching alone (Stommel and Arons 1959a; Pedlosky 1992; Cember 1998). Sverdrup balance only holds far from the boundaries and accounts for little of the net transport compared to the abyssal mixing layer and western boundary current flows, where friction is important.

\section{c. Partially compensating water mass transformations}

The water mass transformation represents the net flow across a buoyancy surface driven by diabatic forcing. Water mass transformation in the PGCM is driven by 1 ) bottom-enhanced turbulent mixing (positive in the 

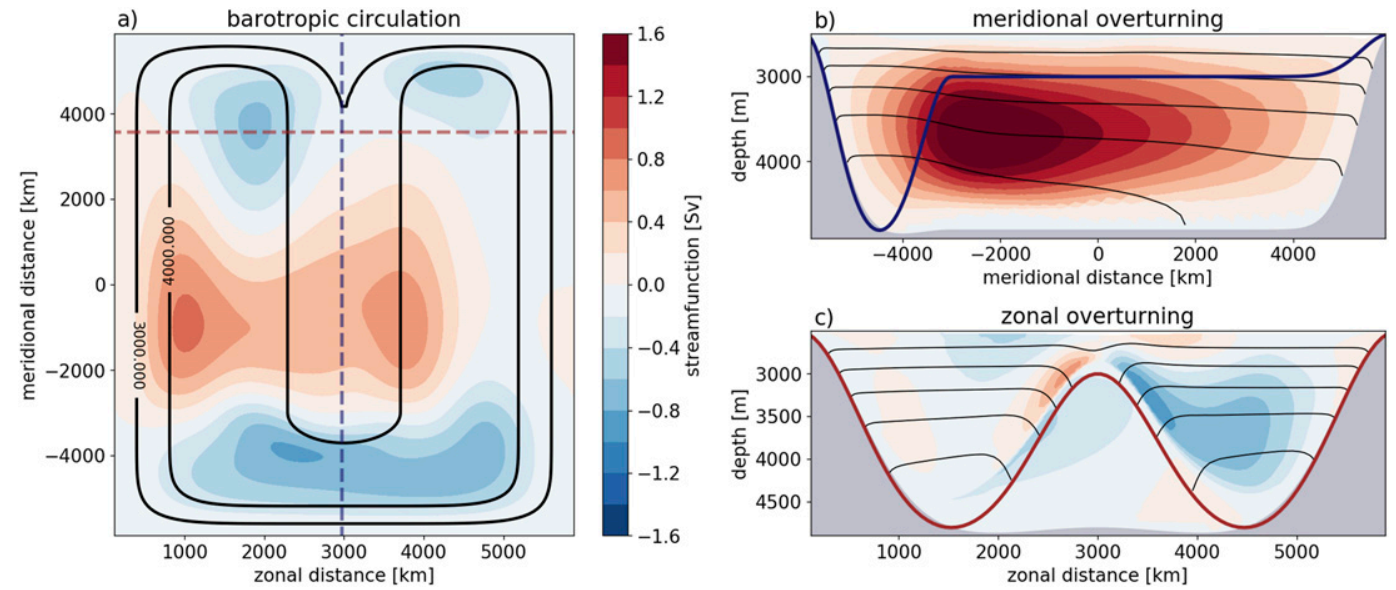

FIG. 4. (a) Barotropic, (b) meridional, and (c) zonal overturning circulations in the PGCM-REAL simulation (see definitions in section $4 \mathrm{~b}$ ). In all cases, positive values (red) correspond to counterclockwise circulations. The blue and red solid lines in (b) and (c), respectively, show the height of the midocean ridge along the dashed lines of the same colors in (a). The thick black lines in (a) are the 3000 and $4000 \mathrm{~m}$ isobaths, which highlight both the continental slopes and the midocean ridge. The thin black lines in (b) and (c) are equally spaced buoyancy surfaces, sampled at $x=L / 4$ and $y=L / 2$, respectively.

net) and 2) restoring to a reference buoyancy profile in the southern restoring region (negative in the net). In the Northern Hemisphere, the restoring rate vanishes by construction and water mass transformation is dominated by the mixing-driven component. Its calculation, following Walin (1982) and Ferrari et al. (2016), is given by

$$
T(b)=\frac{\partial}{\partial b} \int_{V_{b^{\prime}<b}} \nabla \cdot\left(\kappa \nabla b^{\prime}\right) d V,
$$

where $V_{b^{\prime}<b}$ is the volume of water less buoyant than $b$. Water mass transformation is conveniently expressed in units of volumetric transport $\left(\mathrm{m}^{3} \mathrm{~s}^{-1}\right)$ and can be decomposed into various contributions. When applied to regions of bottom-enhanced mixing in the abyss, it is informative to decompose the net water mass transformation into the typically negative contribution (balanced by diapycnal downwelling) in the SML and the typically positive contribution (balanced by diapycnal upwelling) in the BBL (e.g., Ferrari et al. 2016; McDougall and Ferrari 2017). For the purposes of water mass transformation calculations in this paper, we define the BBL as the layer with a convergent buoyancy flux, $\nabla \cdot(\kappa \nabla b)>0$, which extends upward from the seafloor to the level at which buoyancy flux attains its maximum magnitude; the remainder of the ocean is considered the SML and is dominated by a buoyancy flux divergence, $\nabla \cdot(\kappa \nabla b)<0$. For convenience, all water mass transformations in this paper are computed in buoyancy space and remapped into depth space according to the average depth of buoyancy surfaces,

$$
\bar{z}(b)=\frac{1}{A(b)} \int z(b) d A,
$$

which facilitates comparison across simulations with dramatically different stratifications and against the fixed depths of topographic features in the ocean.

The net Northern Hemisphere water mass transformation of $T_{\text {net }}=1.6 \mathrm{~Sv}$ at $3750 \mathrm{~m}$ (Fig. 5a), where it reaches its maximum, is consistent with the depth and magnitude of the maximum of the MOC streamfunction at the equator (Fig. 4b). The net water mass transformation $T_{\text {net }}=T_{\mathrm{BBL}}+T_{\mathrm{SML}}=1.6 \mathrm{~Sv}$ (black line) is the residual of a positive contribution of $T_{\mathrm{BBL}}=2.1 \mathrm{~Sv}$ from the BBL (red line) and a negative contribution of $T_{\mathrm{SML}}=-0.5 \mathrm{~Sv}$ from the SML (blue line), both of which are dominated by the vertical component of the buoyancy flux divergence (dashed lines), i.e.,

$$
T(b)=\partial_{b} \int_{V_{b^{\prime}<b}} \nabla \cdot\left(\kappa \nabla b^{\prime}\right) d V \simeq \partial_{b} \int_{V_{b^{\prime}<b}} \partial_{z}\left(\kappa \partial_{z} b^{\prime}\right) d V .
$$

Virtually all of this transformation occurs on the flanks of the midocean ridge (cf. Figs. 5a,b).

For the convenience of being able to ignore meridional variations in the basin geometry [and their effects on water mass transformations via the "perimeter" effect, as described by Holmes et al. (2018)], we limit the remaining discussion to a domain over $L / 2<x<3 L / 2$ and $0<y<L / 2$ along the Northern Hemisphere midocean ridge, which is responsible for roughly $1 \mathrm{~Sv}$ of the full 

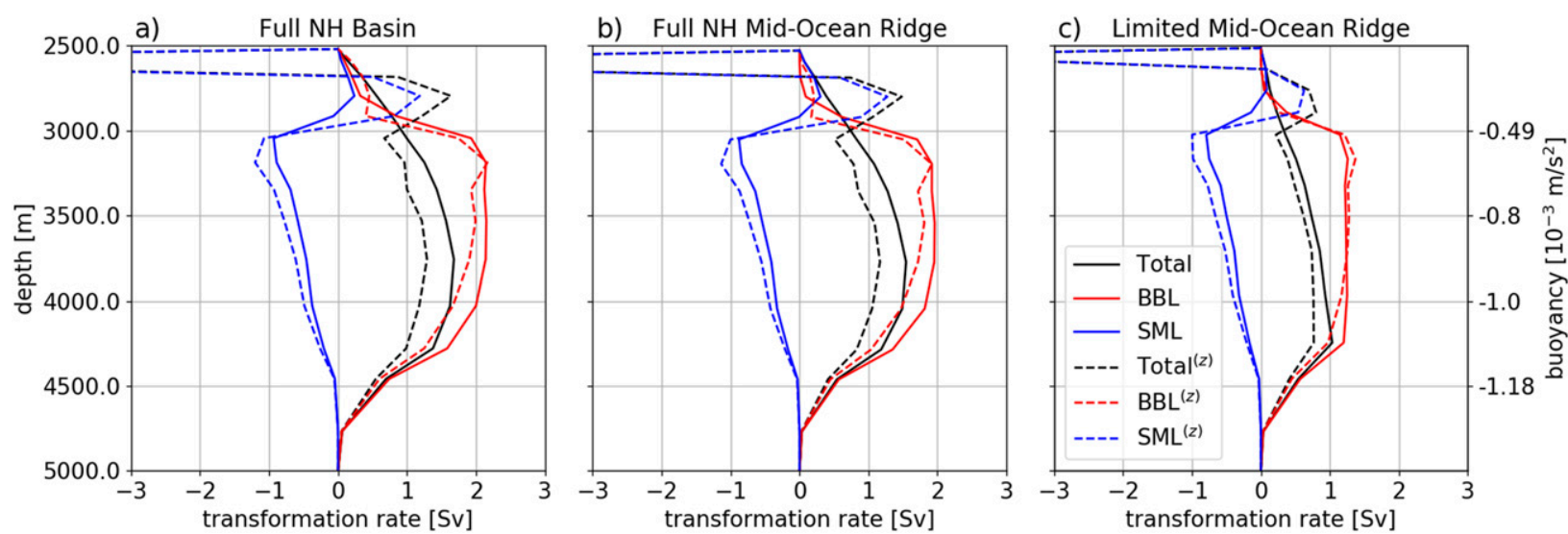

FIG. 5. Water mass transformations from the PGCM-REAL simulation in (a) the full Northern Hemisphere basin ( $y>0$ ), (b) along the Northern Hemisphere midocean ridge $(y>0, L / 2<x<3 L / 2)$, and (c) in a limited water mass analysis region along the Northern Hemisphere midocean ridge $(0<y<L / 2, L / 2<x<3 L / 2)$, as highlighted in Fig. 2 . The black line shows the net water mass transformation, defined by Eq. (18). The red and blue lines show the contributions from the BBL and the SML. The dashed lines show the contributions from only the vertical component of the buoyancy flux. All water mass transformations in the paper are computed in buoyancy space and remapped into depth space [according to Eq. (19)].

basin's transformation (Fig. 5c; limited domain outlined in Fig. 2a).

The net water mass transformation $T_{\text {net }}=1 \mathrm{~Sv}$ at equilibrium is much larger than the $L \Psi_{\mathrm{bg}} \leq 0.1 \mathrm{~Sv}$ predicted by the integral constraint [Eq. (5)] from 1D boundary layer theory. To clarify the discrepancy between the water mass transformations that emerge from the 3D PGCM and the water mass transformations predicted by $1 \mathrm{D}$ dynamics, we emulate the 3D PGCM simulation by solving the $1 \mathrm{D}$ boundary layer equations locally and interpolating the solution onto the 3D PGCM grid.

\section{Emulating the 3D PGCM with local 1D boundary layer models}

\section{a. Boundary layer theory}

Following CF18, we transform the planetary geostrophic equations (6)-(8) from the Cartesian coordinates $(x, y, z)$ to a coordinate system $\left(x^{\prime}, y^{\prime}, z^{\prime}\right)$ aligned with an infinitely extending sea floor at $z=x \tan \theta$, with slope angle $\theta$, and ignoring the southern region restoring condition on buoyancy. The transformation is given by $x^{\prime}=x \cos \theta+$ $z \sin \theta, y^{\prime}=y, z^{\prime}=-x \sin \theta+z \cos \theta$. Buoyancy $b=B(z)+$ $b^{\prime}$ is decomposed into a background $B(z)$ with constant stratification $\partial_{z} B=N_{0}^{2}$ and an anomaly $b^{\prime}\left(z^{\prime}\right)$. The steady state boundary layer equations are thus given by

$$
\begin{aligned}
-f \cos \theta u^{y^{\prime}} & =b^{\prime} \sin \theta-r \cos \theta^{2} u^{x^{\prime}}, \\
f \cos \theta u^{x^{\prime}} & =-r u^{y^{\prime}}, \\
u^{x^{\prime}} N_{0}^{2} \sin \theta & =\partial_{z^{\prime}}\left[\kappa\left(N_{0}^{2} \cos \theta+\partial_{z^{\prime}} b^{\prime}\right)\right],
\end{aligned}
$$

with a no-flux boundary condition $\partial_{z^{\prime}} b^{\prime}+N_{0}^{2} \cos \theta=0$ at the seafloor $z^{\prime}=0$ and decay conditions $\partial_{z^{\prime}} u^{x^{\prime}}, \partial_{z^{\prime}} u^{x^{\prime}}$, $\partial_{z^{\prime}} b^{\prime} \rightarrow 0$ as $z^{\prime} \rightarrow 0$. These equations yield exact analytical solutions for constant $\kappa(\mathrm{CF} 18)$ and approximate analytical solutions for elementary $\kappa(z)$ profiles (Callies 2018).

\section{b. Emulator setup}

We emulate the PGCM solution by using finite differences to solve the time-dependent boundary layer equations (21)-(23) with the local Coriolis parameter $f(y)$ and slope angle $\theta(x, y)$ at each $(x, y)$ cell of the PGCM grid, which is a sensible approach given that the parameters $f(y)$ and $\theta(x, y)$ vary on scales larger than the those of the boundary layer solutions (Dell and Pratt 2015). Since these local boundary layer solutions are given in terms of the local slope-normal direction $z^{\prime}$ rather than the true vertical direction $z$, we project the solution onto the true vertical direction $z$ with the substitution $z^{\prime} \rightarrow z / \cos \theta$ and linearly interpolate from the projected $z$ levels of the boundary layer solution to the PGCM's local $\sigma$ levels. This process provides an emulator of the PGCM which is purely the result of local $1 \mathrm{D}$ dynamics but is regridded to the same grid as the $3 \mathrm{D}$ PGCM and can thus be directly compared.

\section{c. Emulator evaluation}

We evaluate the emulator against the spinup of a PGCM simulation with a constant stratification initial condition $N_{0}^{2}$, hereafter PGCM-CONST. The $1 \mathrm{D}$ emulator accurately reproduces the initial spinup of buoyancy and velocity fields of the PGCM-CONST simulation along most of the midocean ridge flanks, but fails at the 

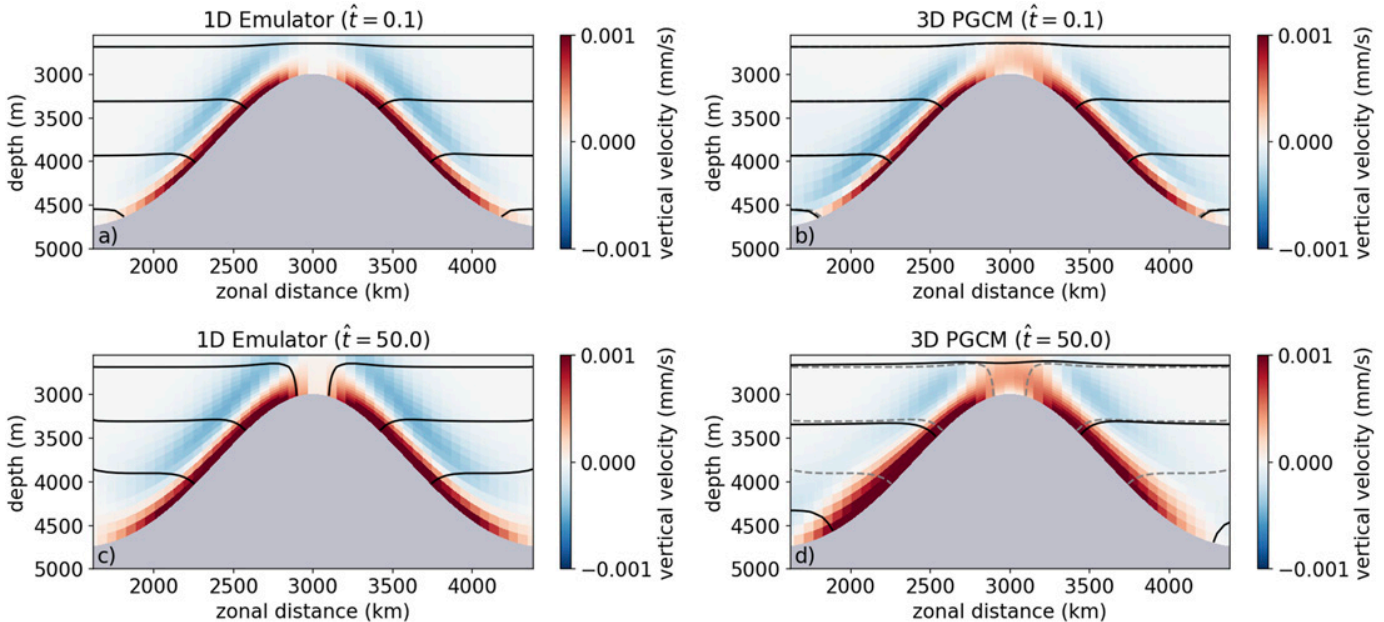

FIG. 6. Vertical velocity (colors) and buoyancy surfaces (black lines) in abyssal mixing layers along a zonal section across the midocean ridge at $y=L / 2$ in (a),(c) the 1D PGCM emulator and (b),(d) the full 3D PGCM, where both are initialized from identical constant stratification buoyancy fields. The top row shows the solutions at an initial time $\hat{t}=0.1$, at which point the abyssal mixing layers have spun up but the basin-scale circulation has not (see section $3 \mathrm{~d}$ ). The bottom row shows the solution at $\hat{t}=50$, at which point the full solution has roughly come to equilibrium with the buoyancy restoring in the Southern Ocean. The predicted buoyancy surfaces in (a) and (c) are reproduced as dashed gray lines in (b) and (d) to show how the 1D emulator predicts the buoyancy field well for short times but that the interior stratification in the PGCM drifts far from the 1D emulator's prediction as it approaches equilibrium.

top and bottom of the ridge where the topographic curvature is large and the cross-slope convergences omitted by $1 \mathrm{D}$ dynamics become important (Figs. 6a,b).

As the solution nears equilibrium, however, the interior basin stratification drifts away from its constant initial value (cf. gray and black contours in Fig. 6d) and the boundary layer flows diverge from the 1D emulator's prediction (Figs. 6c,d). This is expected, as the basin stratification of PGCM-CONST is allowed to evolve in response to the $3 \mathrm{D}$ circulation while the background interior stratification $N_{0}^{2}$ is a constant parameter in the emulator. Relative to the emulator, the equilibrium PGCM-CONST solution exhibits reduced downwelling in the SML and enhanced upwelling in the BBL, both of which contribute to enhancing the net diapycnal upwelling. In section 6 , we use the $1 \mathrm{D}$ emulator to identify properties of the water mass transformations in the PGCM that can be explained by one-dimensional dynamics alone.

\section{The effect of variable interior stratification on the abyssal circulation}

\section{a. What sets the abyssal stratification?}

In our PGCM simulations, the drift of interior buoyancy surfaces over time (Fig. 6d) suggests that the interior stratification at equilibrium may differ substantially from the stratification of the southern region buoyancy profile. Figure 7 a shows the temporal evolution of the horizontally averaged vertical stratification profile, averaged over the Northern Hemisphere basin in the PGCM, where darker greys represent later times. In PGCM-CONST, the abyssal stratification develops substantial vertical structure in the basin over time, despite being rapidly restored back to a constant stratification in the southern restoring region (solid lines, Fig. 7a). Net water mass transformation is initially unbalanced by Eulerian diapycnal flow (cf. Figs. 8b,f) and thus drives changes in the volume of buoyancy layers, which can be interpreted as a component of the diapycnal transport due to the velocity of buoyancy surfaces (Marshall et al. 1999). Excess water mass transformations near the base of the slope destroy the densest layers and expand the deep layers, which translate into a reduction of the stratification that originates at the bottom of the ridge and propagates upward over time. The details of the vertical structure of the equilibrium basin stratification depend on ridge height (not shown), but in all cases the basin stratification increases from zero at the maximum depth (imposed by the no-flux condition at the flat bottom) up to near the restoring reference value of $N_{0}^{2}$ at the top boundary.

The zonal-mean basin stratification develops a significant meridional structure, wherein the zonal-mean stratification along the ridge weakens with distance from 

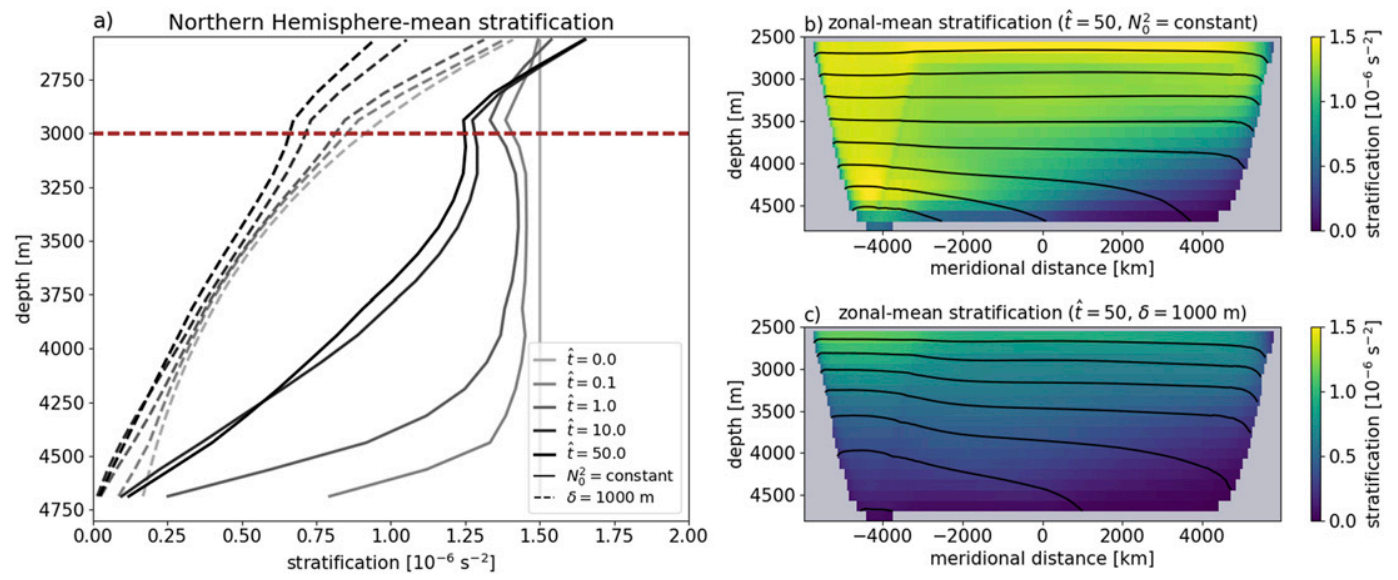

FIG. 7. (a) Temporal evolution and (b),(c) meridional structure of the stratification in PGCM simulations. Grayscale lines in (a) show the temporal evolution of the horizontal-mean stratification in the Northern Hemisphere for simulations with a constant stratification restoring buoyancy profile (solid lines) and a restoring buoyancy profile corresponding to stratification that decays with depth with a scale height of $\delta=1000 \mathrm{~m}$ (dashed lines). The dashed brown line delineates the height of the ridge crest. Panels (b) and (c) show the zonal-mean stratification at equilibrium $\hat{t}=50$ (colors) and equally spaced buoyancy surfaces (black lines) for experiments with restoring to constant and exponential stratification, respectively.

the Southern restoring region (Figs. $7 \mathrm{~b}, \mathrm{c}$ ). In contrast to the mixing layer stratification, which is strongest at the equator and weaker poleward (Callies 2018; CF18), the zonal-mean stratification decreases roughly monotonically with increasing latitude.

Simulations using a reference buoyancy profile that corresponds to an exponential stratification with decay scale of $\delta=1000 \mathrm{~m}$ exhibit much less drift in their stratifications over time (dashed lines, Figs. 7a,b). Although the equilibrium basin stratifications in all of the different PGCM experiments develop vertical structure, there does not seem to be a single preferred equilibrium stratification that depends only on the mixing: both the geometry of the abyssal topography and the restoring
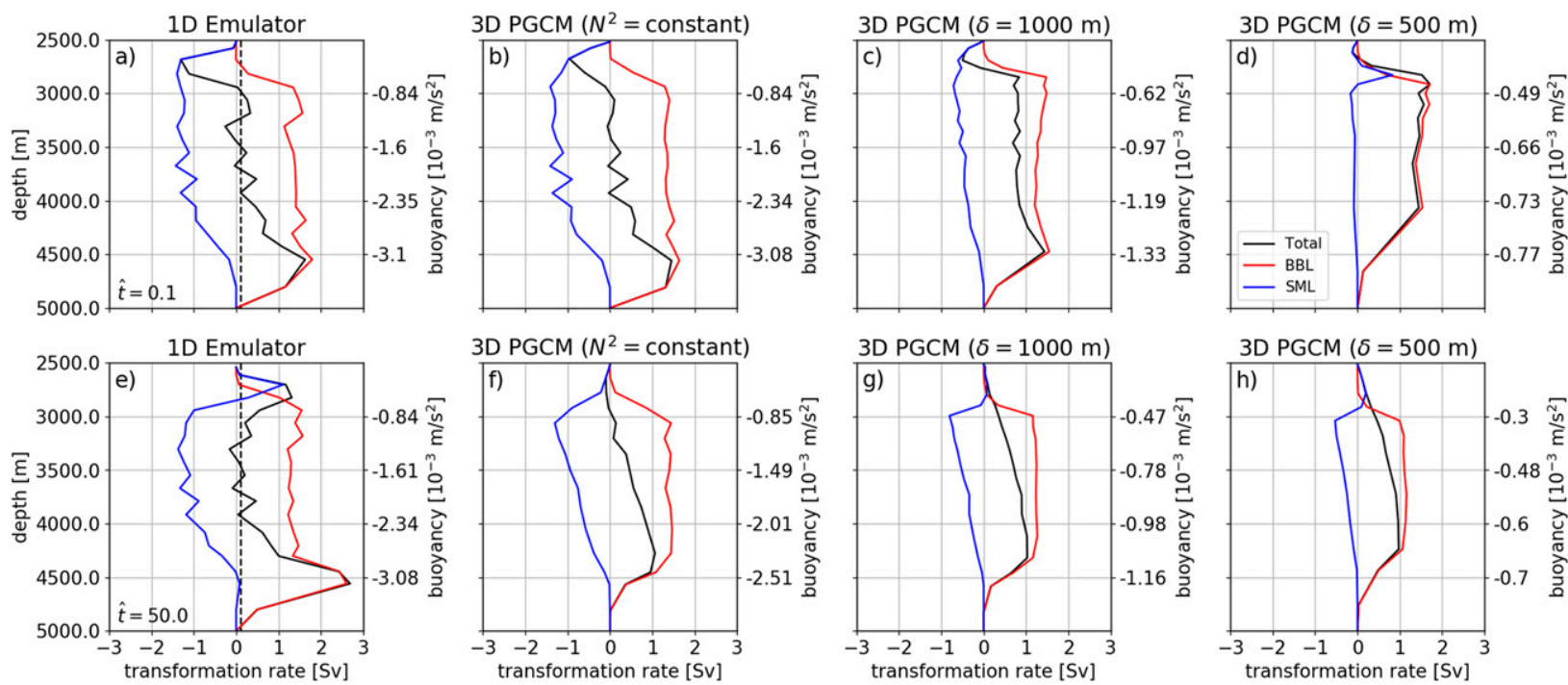

FIG. 8. Water mass transformations in (a),(e) a 1D emulator of the PGCM and (b)-(d),(f)-(h) the 3D PGCM simulations with restoring buoyancy profiles corresponding to stratification profiles with various exponential scale heights $\delta$ (we recover $N^{2}=\operatorname{constant}$ as $\delta \rightarrow \infty$ ). The initial spinup at $\hat{t}=0.1$ is shown in (a)-(d) and the equilibrium state at $\hat{t}=50$ is show in (e)-(h). Black, red, and blue lines show the net, BBL, and SML contributions to the water mass transformations, respectively. The black dashed line in (a) and (e) shows the integral constraint $L \Psi_{\infty}=L \kappa_{\mathrm{bg}} \cot \theta_{\mathrm{max}}$ derived from boundary layer theory, where we take $\theta_{\max }$ as the maximum slope angle of the midocean ridge flank. 

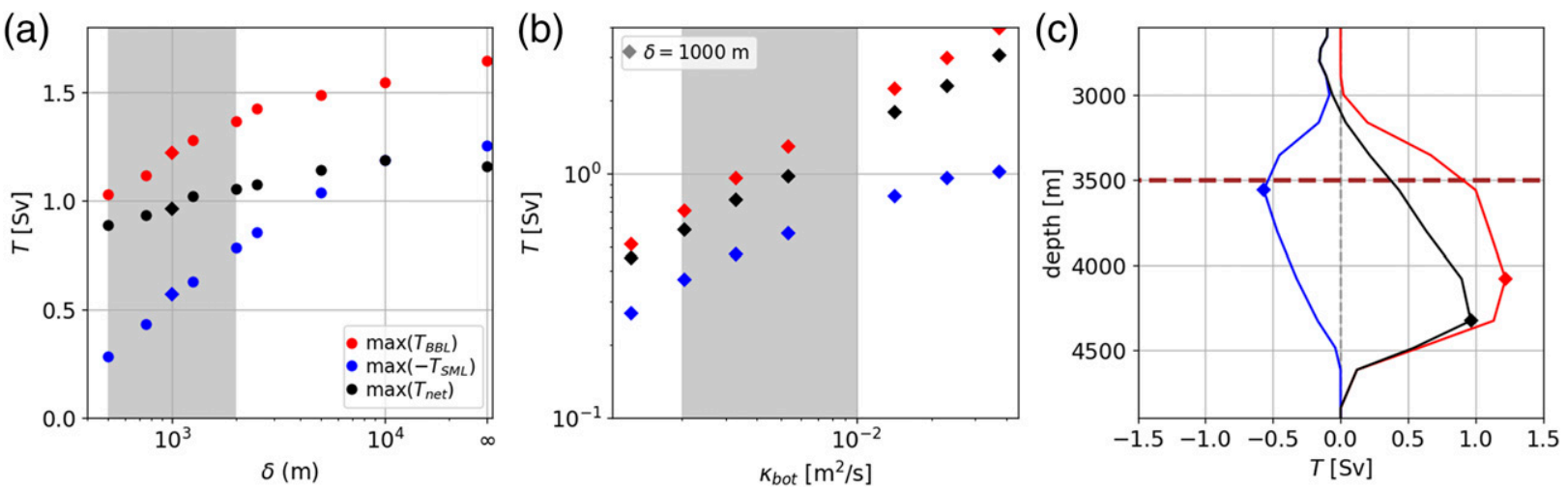

FIG. 9. Scaling of water mass transformations in mixing layers with (a) the height $\delta$ over which the restoring stratification varies and (b) the bottom diffusivity $\kappa_{\text {bot }}$. Colored symbols represent the absolute value of the maximum transport in the BBL (red), the SML (blue), and the net (black), with diamonds representing the PGCM-REAL simulations. The gray shading in (a) represents realistic vertical scales $\delta$ over which abyssal stratification varies and in (b) represents plausible values of the bottom diffusivity $\kappa_{\text {bot }}$. (c) An example of the water mass transformations for a bottom diffusivity $\kappa_{\text {bot }}=5 \times 10^{-3} \mathrm{~m}^{2} \mathrm{~s}^{-1}$, a stratification height scale $\delta=1000 \mathrm{~m}$, and a ridge height of $r_{h}=1500 \mathrm{~m}$, where the corresponding maxima are marked by diamonds and the dashed brown line represents the ridge crest. In all experiments, the maximum net and BBL transformations occur at depths of roughly $4250 \mathrm{~m}$, at the base of the ridge slope, while the maximum SML transformation occurs at the ridge crest.

profile in the southern restoring region influence the interior stratification at equilibrium.

\section{b. Effect of variable stratification on water mass transformations}

We begin by considering the case of transient spinup from a reference buoyancy profile with constant stratification $N_{0}^{2}$, PGCM-CONST. It is useful to consider the evolution of the PGCM during its initial spinup $\left[\hat{t} \simeq\left(\tau_{\mathrm{BL}} / \tau\right)=0.1\right]$ when only mixing layer dynamics are relevant and the solution is thus well predicted by the 1D emulator (Fig. 6). Figure 8a shows the water mass transformations in the $1 \mathrm{D}$ emulator at $\hat{t}=0.1$, which almost exactly predicts the water mass transformations in the full 3D PGCM (Fig. 8b).

Over $-4200 \mathrm{~m}<z<-3000 \mathrm{~m}$, where the slope of the midocean ridge is roughly constant, the near-boundary flow exhibits a vanishingly small net transport (solid black line in Fig. 8a), which is approximately equal to the integral constraint $T_{\text {net }} \simeq L \Psi_{\mathrm{bg}}=L \kappa_{\mathrm{bg}} \cot \theta \leq 0.1 \mathrm{~Sv}$ predicted by $1 \mathrm{D}$ boundary layer theory (dashed black line in Fig. 8a). This vanishingly small net transport is the result of large positive transformation $T_{\mathrm{BBL}}$ (diabatic upwelling, in red) in the BBL and almost-as-large negative transformation $T_{\mathrm{SML}}$ (diabatic downwelling, in blue) in the SML. Below $z=-4200 \mathrm{~m}$, at the base of the topographic slope, abyssal bottom waters feed the upwelling in the BBL and the maximum net water mass transformation is well predicted by the strictly upwelling transport in the bottom boundary layer from 1D theory (Figs. 8a,b), as suggested by CF18.

For the spinup from a reference stratification that increases exponentially with height (as is almost ubiquitously the case in the abyssal ocean), the integral constraint [Eq. (5)] no longer holds at $\hat{t}=0.1$ and the solution already exhibits a net transformation much larger than $L \Psi_{\mathrm{bg}}$ at all depths from the base of the slope to the ridge crest (Figs. 8c,d). The increase in the net transformation, which spans the full vertical extent of the ridge, is primarily due to a decrease in the downwelling in the SML which, in the extreme case of an exponential scale height of $\delta=500 \mathrm{~m}$ for the reference stratification, vanishes completely (Fig. 8d). The strongly positive net transformation is primarily due to the buoyancy convergence driven by the rapid increase of the initial stratification with height, i.e., $\kappa \partial_{z z} B>0$ reduces the divergence $\nabla \cdot(\kappa \nabla b)<0$ due to $\partial_{z} \kappa<0$ in the SML (see also Fig. 14).

As these solutions reach equilibrium, they retain a finite net transformation at all depths from the base of the slope to the ridge crest, slightly reduced by gradually strengthening negative transformations in the SML (cf. Figs. 8g,h to Figs. 8c,d). At equilibrium, we find the degree of compensation near the ridge crest depends on the vertical scale over which the restoring stratification varies (within a range applicable to the ocean): the more rapidly the stratification increases with height, the less upwelling in the BBL is compensated by downwelling in the SML (Figs. 8f-h and 9a). In contrast, upwelling in the BBL is remarkably invariant to vertical variations in the stratification and remains a reasonable prediction for the maximum net transformation (Figs. 9a,b), which occurs at the base of the slope where the compensating downwelling contribution from the SML vanishes (Fig. 9c). Thus, while the maximum net water mass transformation is accurately predicted by upwelling in the BBL alone, the 

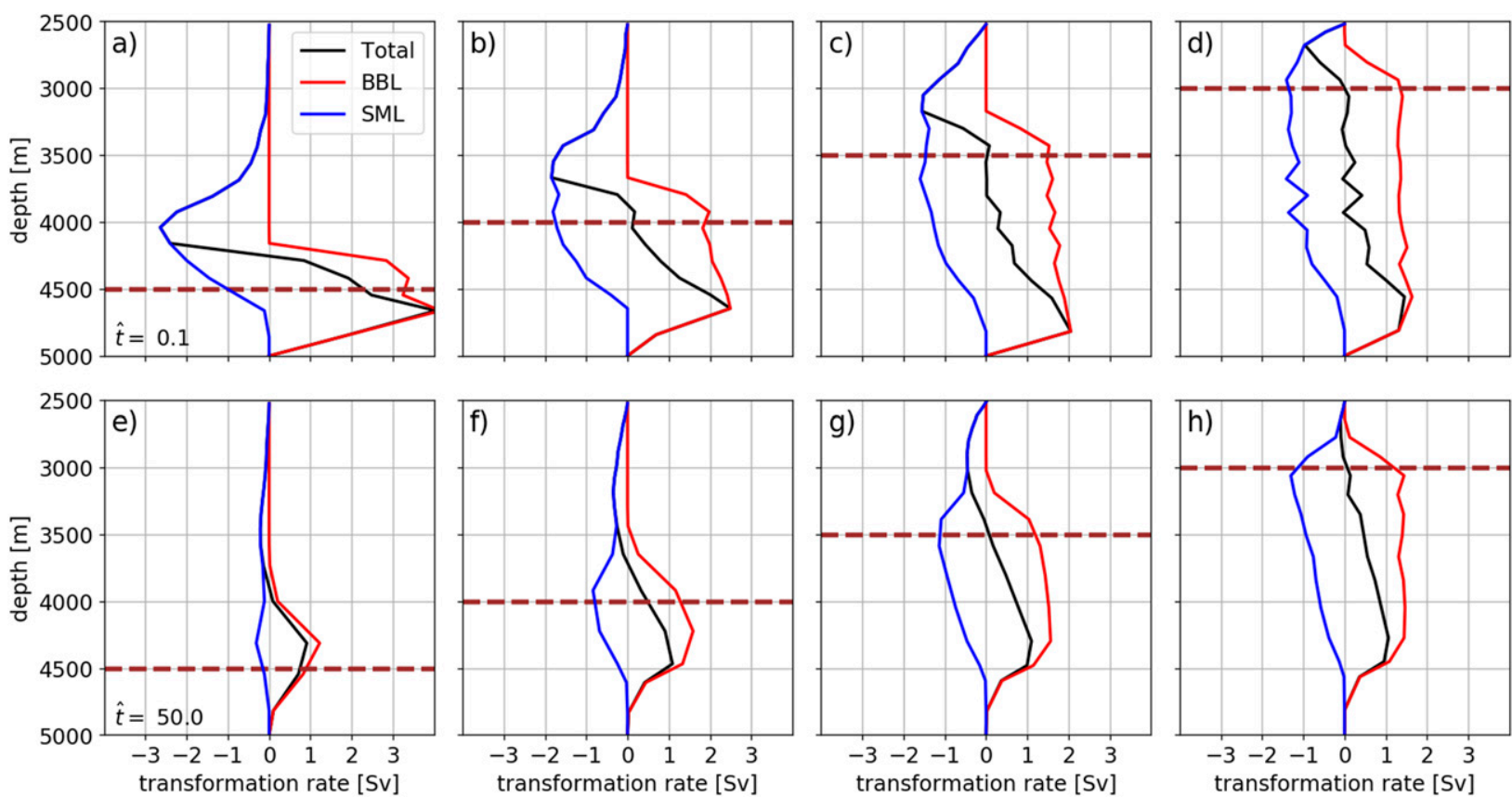

FIG. 10. Water mass transformations in PGCM simulations as a function of ridge height. All panels are for a fixed constant stratification restoring buoyancy profile. (a)-(d) The initial spinup at $\hat{t}=0.1$ and (e)-(h) the equilibrium state at $\hat{t}=50$. Midocean ridge height increases in increments of $500 \mathrm{~m}$ from left to right, as indicated by the dashed brown lines. Black, red, and blue lines show the net, BBL, and SML contributions to the water mass transformations, respectively.

vertical structure and extent of water mass transformations depend also on downwelling in the SML, which itself is strongly dependent on the vertical stratification, and is not predicted by $1 \mathrm{D}$ theory.

\section{c. Vertical extent of overturning set by ridge height}

We have shown that most of the water mass transformation occurs within abyssal mixing layers along the midocean ridge (Figs. 5a,b). We further hypothesize that variations in the height of the ridge modulate the vertical extent of abyssal water mass transformations and thus the vertical extent of the abyssal overturning cell. We test this hypothesis by running variations of the PGCM-CONST where we vary the ridge height from 500 to $2000 \mathrm{~m}$, in increments of $500 \mathrm{~m}$. In the initial spinup, largely compensating positive and negative transformations develop in the BBL and SML, respectively, from the base of the ridge slope up to the ridge crest (Figs. 10a-d). The net transformation below the ridge crest vanishes according to the integral constraint [Eq. (5)], except near the seafloor where bottom water feeds into the BBL. At equilibrium, however, the stratification drifts away from its constant reference state (e.g., Fig. 7) and permits a finite net transformation (Figs. 10e-h), which spans the full vertical extent of the ridge. The result that the vertical extent of the abyssal MOC follows the vertical extent of the midocean ridge is consistent with
Lumpkin and Speer's (2007) global inversion for the MOC, which shows that the vertical extent of the Atlantic and Indo-Pacific lower MOC cells appear to closely follow the vertical extent of their respective major bathymetric features (i.e., midocean ridges).

\section{Comparison with realistic midocean ridges}

The topography and mixing in the PGCM is inspired by observations from the Brazil Basin (Fig. 11), one of the regions of the abyssal ocean best characterized by observations (e.g., St. Laurent et al. 2001; Thurnherr and Speer 2003). The circulation that emerges from the PGCM-REAL simulation (Fig. 11b) is qualitatively similar to the circulation inferred from observations using an inverse model (Fig. 11a, based on St. Laurent et al. 2001): bottom-enhanced mixing along the slope of the midocean ridge drives upwelling in a bottom boundary layer and downwelling in a stratified mixing layer above.

To contextualize our simulated water mass transformations, we estimate water mass transformations in the ocean based on hydrography and a commonly used mixing parameterization, following Ferrari et al.'s (2016) modifications of Nikurashin and Ferrari (2013). The buoyancy flux is parameterized by $\overline{w^{\prime} b^{\prime}}=-\Gamma \varepsilon$, where $\varepsilon$ is the kinetic energy dissipation and $\Gamma$ is a 

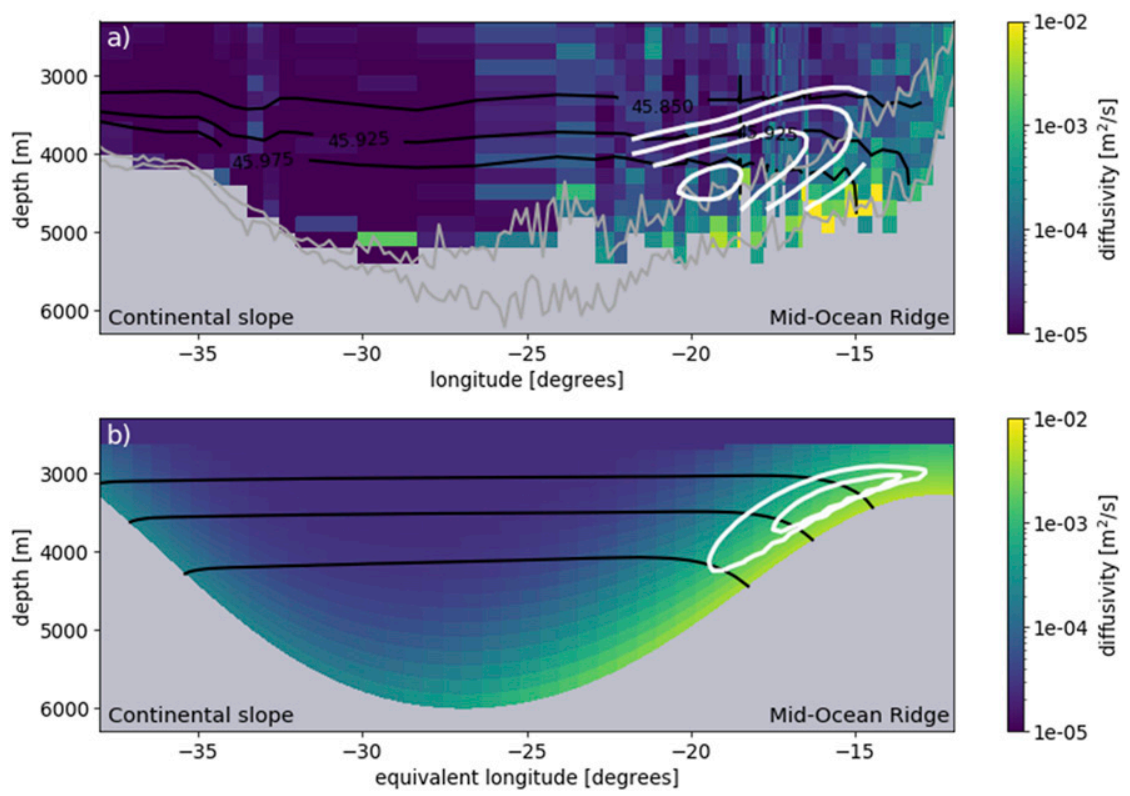

FIG. 11. Diabatic zonal overturning circulation driven by bottom-enhanced mixing on the western flank of a midocean ridge in (a) the South Atlantic Ocean and (b) the western half of the PGCM-REAL simulation domain. White lines show arbitrarily chosen contours of the counterclockwise zonal overturning streamfunction, where the values for (a) are digitized from Fig. 14 of St. Laurent et al. (2001) and for (b) are diagnosed from PGCM-REAL simulation. Coloring shows the vertical diffusivity in log scale (light gray shading represents depths with no microstructure measurements and does not necessarily represent topography), where (a) is inspired by Fig. 2 of Polzin et al. (1997) and the diffusivity is calculated with microstructure profiles from the BBTRE experiment (archived at https://microstructure.ucsd.edu/\#/; Polzin et al. 1997; St. Laurent et al. 2001). Black lines in (a) are potential density $\sigma_{4}$ surfaces (referenced to $4000 \mathrm{~m}$ ) from the microstructure profiles and in (b) buoyancy surfaces from the PGCM solution, chosen arbitrarily to show that the zonal overturning circulation is indeed diabatic. The dark gray lines in (a) show the depth minimum (canyon thalweg) and maximum (canyon crest) seafloor depth within $0.5^{\circ}$ latitude of the microstructure profiles. In (b), zonal distance along the PGCM section has been converted to an equivalent longitude at $25^{\circ} \mathrm{S}$ so that length scales can be directly compared between the two panels.

"mixing efficiency" set to $\Gamma=0.2$ (Osborn 1980); the buoyancy field (computed from the neutral density $\gamma$ ) is taken from a gridded product derived from hydrographic sections of the World Ocean Circulation Experiment (Gouretski and Koltermann 2004); and we impose the insulating bottom boundary condition $\mathbf{n} \cdot \overline{\mathbf{u}^{\prime} b^{\prime}} \simeq \overline{w^{\prime} b^{\prime}}=0$ (where $\mathbf{n} \simeq \mathbf{z}$ for typical bathymetric slopes of $\tan \theta \ll 1$ ). The dissipation rate $\varepsilon$ is produced by applying linear wave radiation theory for internal tides (Nycander 2005) and lee waves (Nikurashin and Ferrari 2011) and assuming a fraction $q=0.3$ of the radiated energy is locally dissipated according to a bottom-enhanced structure function with a height scale of $500 \mathrm{~m}$ (St. Laurent and Garrett 2002). We compare water mass transformation estimates from the ocean with estimates from PGCM-REAL, a simulation with restoring to an exponential reference stratification with a decay scale of $1000 \mathrm{~m}$ and which is our simulation with a stratification in the southern restoring region most similar to the Southern Ocean's (Fig. 2c). We focus on rectangular regions with dimensions $3000 \mathrm{~km} \times 3000 \mathrm{~km}$ (in the PGCM) or $30^{\circ}$ longitude $\times 30^{\circ}$ latitude (in the ocean), which encompass comparable ridge lengths and surface areas at subtropical latitudes. Water mass transformations in the PGCM-REAL simulation (Fig. 12a) are the result of partially compensating buoyancy flux convergence (Fig. 12e) in the BBL (red colors) and buoyancy flux divergence in the SML (blue colors). Qualitatively similar (but noisier) water mass transformations emerge for the midocean ridge regions in the Pacific, Atlantic, and Indian Oceans (Figs. 12b-d, regions delineated by boxes Figs. 12e,f). While the net transformation varies from $0.5 \mathrm{~Sv}$ in the South Pacific region to $2 \mathrm{~Sv}$ in the Indian Ocean region, the net transformation is always the result of partially compensating upwelling and downwelling. This qualitative similarity emerges in 

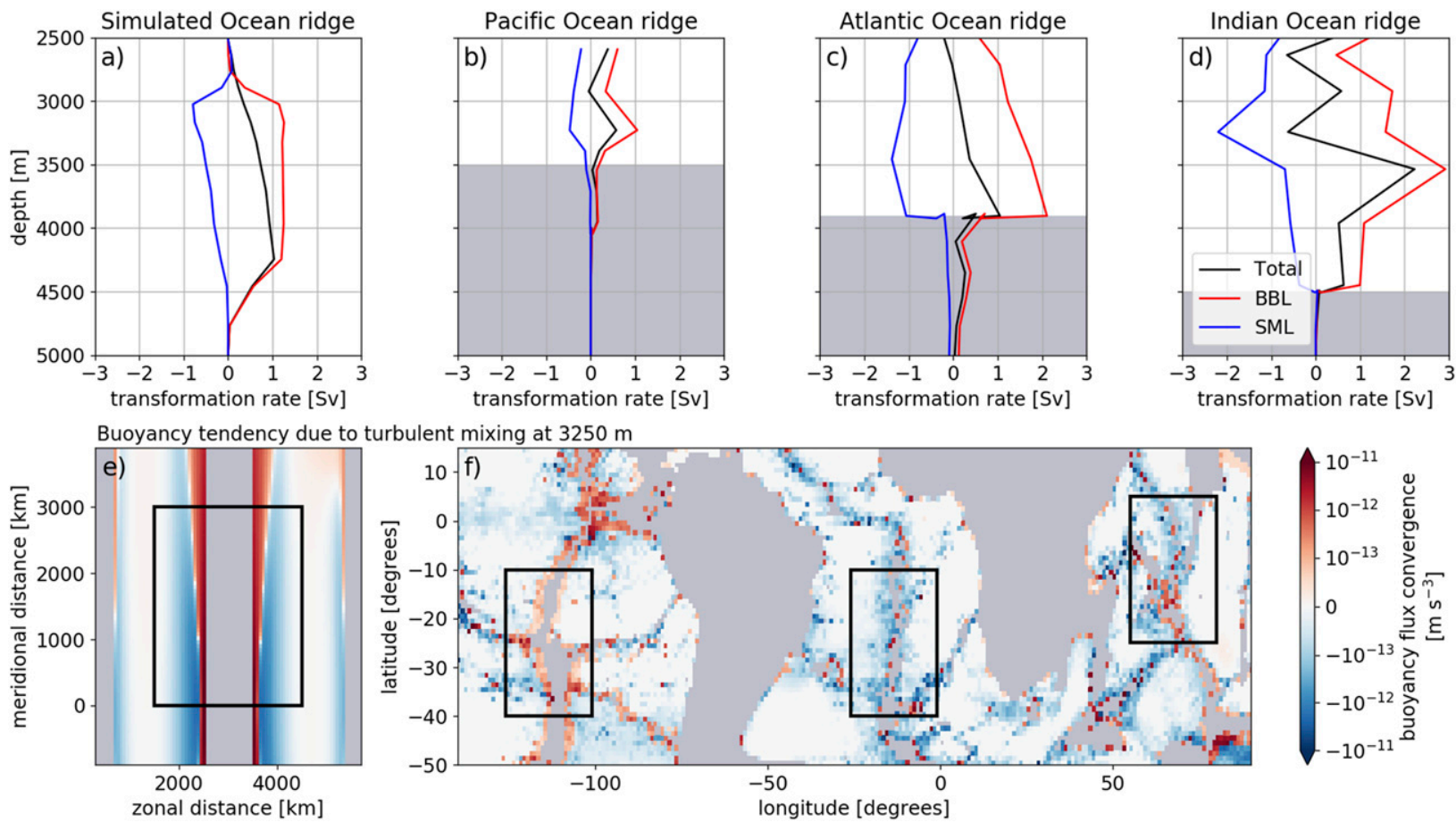

FIG. 12. (top) Water mass transformations at all abyssal depths and (bottom) buoyancy flux convergence at $3250 \mathrm{~m}$ depth in similarly sized domains containing midocean ridges, as diagnosed from (a),(e) the PGCM-REAL simulation and estimated for the (b),(f) Pacific, (c),(f) Atlantic, and (d),(f) Indian Oceans. In (a)-(d), the black, red, and blue lines show the net, BBL, and SML contributions to the water mass transformations, respectively (gray shaded indicates depths representing very little ocean volume). The black boxes in (e) and (f) delineate the similarly sized regions (each with dimensions of roughly $3000 \mathrm{~km} \times 3000 \mathrm{~km}$ ) for which we compute the water mass transformations. In (e) and (f), red and blue show regions of buoyancy flux convergence (positive buoyancy tendency) and buoyancy flux divergence (negative buoyancy tendency), respectively.

the large-scale water mass diagnostic, despite the relatively heterogeneous nature of the estimated buoyancy flux and topography in the ocean basins (cf. Figs. 12f,e), because in all cases the turbulent buoyancy flux is bottom enhanced (driving downwelling) and tapers to zero over the last grid cell to meet the insulating boundary condition within some bottom boundary layer (driving upwelling). This property of compensating water mass transformations is in contrast to the case of a constant buoyancy flux (Ferrari et al. 2016; Holmes et al. 2018), in which there is no compensating downwelling. Estimates of global abyssal water mass transformations, however, exhibit stronger compensation by downwelling in the SML than shown here for midocean ridge regions [by factors of 2 and 3 for Ferrari et al. (2016) and McDougall and Ferrari (2017), respectively]. In section 8 we present evidence in support of McDougall and Ferrari's (2017) speculation that much of this discrepancy arises due to the effects of correlations between the buoyancy flux and the stratification, which are omitted in their calculations. Ferrari et al.'s (2016) estimate includes these correlation terms but relies on poorly sampled knowledge of the buoyancy flux and stratification close to the seafloor, which likely introduces substantial uncertainty in their estimate. While much work has gone into understanding how the compensation factor depends on various parameters of the diagnostic approach based on climatological observations and parameterized mixing (McDougall and Ferrari 2017; Holmes et al. 2018; Cimoli et al. 2019), the functional dependence of the compensation factor in the prognostic dynamic approach has received comparably little attention and is not well known.

\section{Classic recipes and new trends in abyssal cuisine}

Quantitative study of the abyssal stratification began with the classic study of Munk (1966): a point-wise theory in which the observed abyssal stratification is the result of a balance between uniform upwelling and a uniform turbulent vertical mixing. As anticipated by Munk (1966), subsequent observations show turbulent mixing to be strongly heterogeneous, with an emerging pattern of weak background mixing and vigorous mixing near rough topography (Polzin et al. 1997; Waterhouse et al. 2014). In light of these observations, 
Munk and Wunsch (1998) revisited Munk's (1966) theorized point-wise vertical balance and rederive it as a horizontally averaged buoyancy budget, which we transcribe as

$$
\langle w\rangle A \simeq\left\langle N^{2}\right\rangle^{-1} \frac{d}{d z}\left[A(z)\langle\kappa\rangle\left\langle N^{2}\right\rangle\right]
$$

in our notation, where the key assumption is that correlations between the turbulent diffusivity $\kappa$, the stratification $N^{2}$, and the vertical velocity $w$ are all assumed to be negligible, such that $\left\langle w N^{2}\right\rangle=\langle w\rangle\left\langle N^{2}\right\rangle$ and $\left\langle\kappa N^{2}\right\rangle=$ $\langle\kappa\rangle\left\langle N^{2}\right\rangle$. In Figs. 13a-c, we show, respectively, the three terms in Eq. (24): the horizontally averaged stratification $\left\langle N^{2}\right\rangle$, the turbulent buoyancy flux $\langle\kappa\rangle\left\langle N^{2}\right\rangle$, and the isobath surface area (ocean area at a fixed depth) $A(z)$. In Fig. 13d, we show the left- and right-hand sides of Eq. (24) in the PGCM-REAL simulation at equilibrium. The horizontally averaged vertical flux divergence [righthand side of Eq. (24)] is a poor prediction for the diagnosed vertical transport. This is not surprising, given that 1) $w, N^{2}$, and $\kappa$ are spatially correlated in our solutions and 2) that density surfaces are strongly sloping near boundaries. Analysis in buoyancy coordinates, such as either the thickness-weighted average framework (De Szoeke and Bennett 1993; Young 2012) or the water mass transformation framework (Walin 1982), are more appropriate. The mixing-driven water mass transformation (solid black line) equals the diapycnal transport (the diabatic MOC of interest here), by definition, but also serves as a better approximation of the vertical transport $\langle w\rangle A$ than the right-hand side of Eq. (24).

In Fig. 13c, we show that ignoring correlations within the buoyancy flux $\left\langle\kappa N^{2}\right\rangle \approx\langle\kappa\rangle\left\langle N^{2}\right\rangle$ introduces large biases relative to the full horizontal-mean buoyancy flux, which results in even larger biases in the flux divergence (Fig. 13d). To investigate the role of these spatial correlations between $\kappa$ and $N^{2}$ more exactly, we return to the water mass transformation framework, where we now define $\langle\cdot\rangle \equiv A_{b}^{-1} \int_{A_{b}} \cdot d A$ as the average along a buoyancy surface. Following Holmes et al. (2018), we can thus decompose the vertical component of the water mass transformation into uncorrelated and correlated components, respectively:

$$
T_{\mathrm{net}} \approx \partial_{b}\left(A\left\langle\kappa \partial_{z} b\right\rangle\right)=\partial_{b}\left(A\langle\kappa\rangle\left\langle\partial_{z} b\right\rangle\right)+\partial_{b}\left(A\left\langle\kappa^{\prime} \partial_{z} b^{\prime}\right\rangle\right),
$$

where $\kappa^{\prime}=\kappa-\langle\kappa\rangle$ and $\partial_{z} b^{\prime}=\partial_{z} b-\left\langle\partial_{z} b\right\rangle$ are deviations from the mean along a buoyancy surface. Figures 14a and $14 \mathrm{c}$ show that ignoring the correlation terms in the water mass transformation results in an overestimation of the net transformation by $20 \%-200 \%$ because the stratification $\partial_{z} b^{\prime}$ is locally reduced in the abyssal mixing layers where $\kappa^{\prime}$ is high (orange lines in Figs. 14a,c), with the magnitude of this bias varying dramatically across simulations with different topographic geometries and restoring profiles.

To support our hypothesis that vertical variations in the stratification are necessary to support large net water mass transformations, we further decompose the uncorrelated component into a component related to the change in the mean stratification and a residual component related to changes in both the area of the buoyancy surface and the mean diffusivity:

$$
\partial_{b}\left(A\langle\kappa\rangle\left\langle\partial_{z} b\right\rangle\right)=A\langle\kappa\rangle \partial_{b}\left\langle\partial_{z} b\right\rangle+\left(\partial_{z} b\right) \partial_{b}(A\langle\kappa\rangle) .
$$

In the experiment shown in Figs. 14a and 14b, where the uncorrelated component is a reasonable approximation of the net transformation, we find the net transformation to be largely driven by variations of the stratification with buoyancy, $A\langle\kappa\rangle \partial_{b}\left\langle\partial_{z} b\right\rangle$, although variations in the diffusivity integrated along a buoyancy surface are also important. Variations in the stratification also appear important in the experiment shown in Fig. 14d, although this decomposition is more difficult to interpret since the uncorrelated component overestimates the net transformation by a factor of 3 (Fig. 14c).

\section{Discussion}

The idealized numerical model presented here describes an abyssal circulation and stratification controlled by mixing-driven flows along a midocean ridge in a crossequatorial basin (Fig. 1). By initializing with—and restoring to-a series of reference buoyancy profiles in the south of the basin, we investigate transient and equilibrium coupling between the basin stratification and the mixingdriven boundary flows. At equilibrium, dense abyssal waters form in the southern restoring region and flow north via adiabatic deep western boundary currents (DWBCs; red circle), filling the abyssal depths in both hemispheres. Along the midocean ridge, bottom-enhanced mixing (squiggly lines) drives a net transformation of dense abyssal waters into lighter deep waters, the residual of partially compensating upwelling in a bottom boundary layer (BBL) and downwelling in a stratified mixing layer (SML) right above it. The newly formed light deep waters flow zonally toward the western continental slope (solid arrow), returning southward via an adiabatic deep western boundary current to the restoring region (blue circles), and closing the abyssal overturning circulation as they are once again transformed into dense abyssal waters.

Despite the extreme degree of idealization in our formulation of the planetary geostrophic circulation model (PGCM), the water mass transformations that 

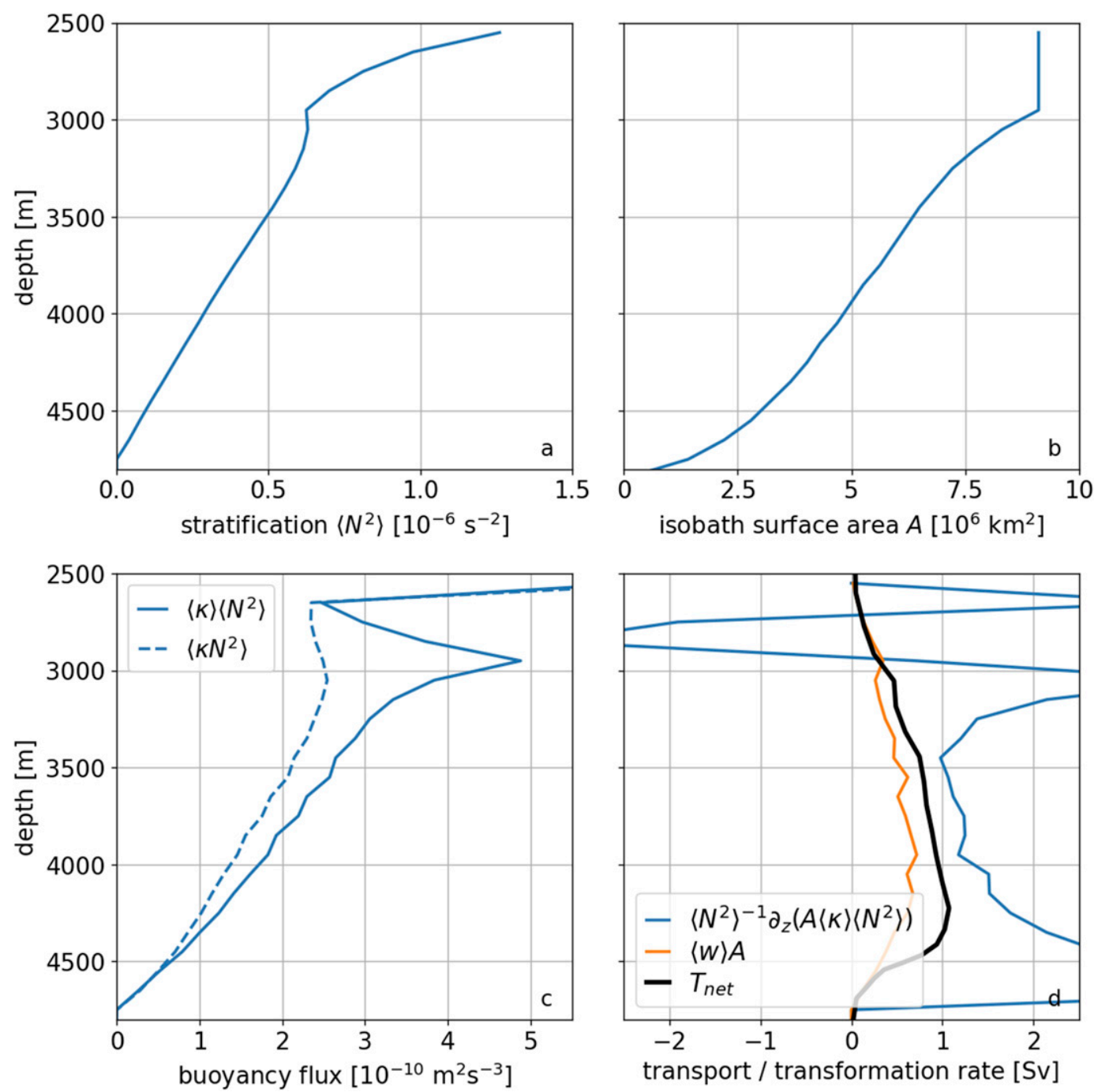

FIG. 13. Comparison of abyssal upwelling diagnostics in the PGCM-REAL simulation for the water mass transformation analysis region highlighted in Fig. 2a. The orange and blue lines in (d) represent the left- and right-hand sides, respectively, of the horizontally averaged advection-diffusion balance $\langle w\rangle A \simeq\left\langle N^{2}\right\rangle^{-1}(d / d z)\left[A(z)\langle\kappa\rangle\left\langle N^{2}\right\rangle\right]$ [Eq. (24)], which accounts for changes in isobath surface area $A(z)$ with depth but ignores correlations between $w$, $\kappa$, and $N^{2}$ and excludes the horizontal advection. The solid blue lines in (a)-(c) show the individual components of the expressions: (a) the horizontally averaged stratification $\left\langle N^{2}\right\rangle$, (b) the horizontally averaged buoyancy flux $\langle\kappa\rangle\left\langle N^{2}\right\rangle$, and (c) the isobath surface area $A(z)$. The dashed line in (b) shows the role of correlation terms $\left\langle\kappa N^{2}\right\rangle-\langle\kappa\rangle\left\langle N^{2}\right\rangle$ in setting the vertical structure of the buoyancy flux. Finally, the solid black line in (d) shows the net water mass transformation, where its native density coordinate has been mapped into a pseudodepth coordinate by taking the average depth of a given buoyancy surface [Eq. (19)]. For all of our simulations, vertical advection-diffusion bulk models are poor approximations of diapycnal abyssal upwelling.

emerge at equilibrium are qualitatively similar to diagnostic estimates of water mass transformations near midocean ridges in the Pacific, Atlantic, and Indian Oceans (Fig. 12), which are themselves fairly uncertain (Cimoli et al. 2019). Similarly, the zonal overturning that emerges within bottom mixing-driven flows along the midocean ridge are qualitatively similar to that described by an inverse model of the abyssal Brazil Basin based on in situ measurements (St. Laurent et al. 2001, and Fig. 11). Remaining differences between our simulations and observations are likely due to the crude nature of our parameterizations for the restratification by submesoscale turbulence and for the formation of bottom waters in the Southern Ocean, as well as uncertainties in the observational estimates.

The equilibrium interior stratification in the PGCM always exhibits dynamically significant vertical variations, the structure of which is determined by a combination of 

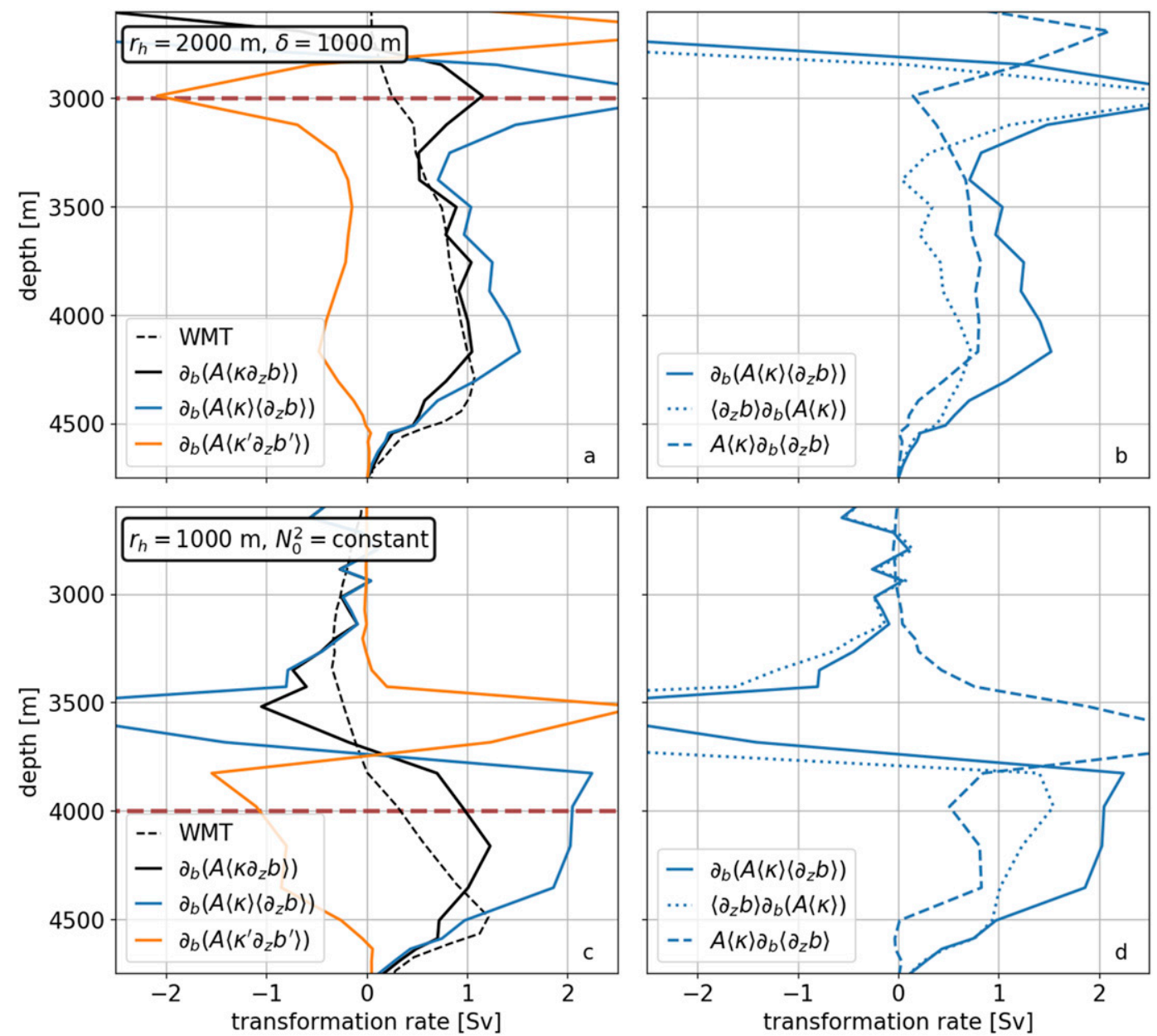

FIG. 14. Decomposition of the water mass transformation into various physical components in (a),(b) the PGCM-REAL experiment and (c),(d) an experiment with a shorter ridge and constant reference stratification. In (a) and (c), we approximate the full water mass transformation (dashed black) by the contribution from the vertical buoyancy flux $\partial_{b}\left(A\left\langle\kappa \partial_{z} b\right\rangle\right)$ (solid black), which we then decompose into an uncorrelated component $\partial_{b}\left(A\langle\kappa\rangle\left\langle\partial_{z} b\right\rangle\right)$ (solid blue) and a residual $\partial_{b}\left(A\left\langle\kappa^{\prime} \partial_{z} b^{\prime}\right\rangle\right)$ (solid orange), where $\langle\cdot\rangle$ denotes averaging along a buoyancy surface. In (b) and (d), we further decompose the uncorrelated component into contributions due to the buoyancy derivative of the mean stratification $\partial_{b}\left\langle\partial_{z} b\right\rangle$ (dashed) and the integrated diffusivity along a buoyancy surface $\partial_{b}(A\langle\kappa\rangle)$ (dotted).

mixing layer dynamics and the restoring condition in the south. Even in our simulations that are initialized from - and restored to - a constant stratification reference buoyancy profile, heterogeneities in the topographic slope cause cross-slope divergence and a corresponding exchange flow between the abyssal mixing layers and the interior. Over time, these exchange flows modify the interior stratification and associated water mass transformations.

As in CF18, we find the prediction of upwelling in the BBL by one-dimensional (1D) boundary layer theory provides a reasonable approximation to the maximum net transformation or, equivalently, the strength of the diabatic meridional overturning circulation (Figs. 8 and 9). While this interpretation provides a useful prediction for the maximum net transformation which occurs at the base of topographic slopes, it does not inform the net transformation along the flanks of the midocean ridge, where upwelling in the BBL is instead partially compensated by downwelling in a SML. At depths where both the BBL and the SML are active, 1D theory predicts almost perfect compensation and a resulting net transformation that is vanishingly small [Eq. (5) and Figs. 8a,e]. In contrast, our PGCM simulations exhibit finite net water mass transformations that extend from the base of the ridge slopes all the way up to the ridge crest (Fig. 10), consistent with both our oceanic estimates (Fig. 12) and inverse models of the Indo-Pacific overturning circulation (Lumpkin and Speer 2007). We attribute the existence of a finite net transformation to vertical variations in the basin stratification (Figs. 8 and 14). As we increase 
the degree to which the restoring stratification varies in the vertical, the compensation of BBL upwelling by SML downwelling (evaluated near the depth of the ridge crest) ranges from nearly perfect compensation to nearly zero compensation (Fig. 9a). Thus, while 1D bottom boundary layer theory provides a reasonable approximation to maximum net water mass transformation, the vertical extent and structure of water mass transformations depends on the degree of compensation by downwelling in the SML, which is itself coupled to the vertically varying basin stratification.

Our simulations show that correlations between mixing and stratification (Figs. 14a,c), which are typically ignored in idealized models of the zonal-mean abyssal overturning (Nikurashin and Vallis 2011; Jansen and Nadeau 2019), can be of leading-order importance in abyssal water mass transformations; whether these correlations are important in the ocean remains an open question. Despite our improved understanding of the roles of bottom mixing and the interior basin stratification on the abyssal water mass transformations and circulation, we fall short of a predictive analytical theory for the abyssal overturning and stratification that couples boundary layer dynamics with a model for the evolution of the interior stratification. Recent and ongoing work in 1) observing abyssal mixing layers (e.g., Garabato et al. 2019), 2) investigating their dynamics with idealized theory and simulations (Wenegrat et al. 2018; Callies 2018; Holmes et al. 2019), 3) developing and evaluating parameterizations of their turbulent fluxes, 4) and coupling them to the basin stratification [e.g., refining the approach of Salmun et al. (1991)] will all be key ingredients for cooking up a revised theory of the abyssal circulation and stratification.

Acknowledgments. We thank Ali Mashayek, Laura Cimoli, Xiaozhou Ruan, Bryan Kaiser, and Ryan Holmes for insightful discussions about abyssal mixing layers. We are grateful for two reviewers whose feedback improved the manuscript. We acknowledge funding support from National Science Foundation Awards 6932401 and 6936732 .

\section{REFERENCES}

Abernathey, R. P., D. Ferreira, and A. Klocker, 2013: Diagnostics of isopycnal mixing in a circumpolar channel. Ocean Modell., 72, 1-16, https://doi.org/10.1016/j.ocemod.2013.07.004.

, I. Cerovecki, P. R. Holland, E. Newsom, M. Mazloff, and L. D. Talley, 2016: Water-mass transformation by sea ice in the upper branch of the Southern Ocean overturning. Nat. Geosci., 9, 596-601, https://doi.org/10.1038/ngeo2749.

Archer, D., H. Kheshgi, and E. Maier-Reimer, 1998: Dynamics of fossil fuel $\mathrm{CO}_{2}$ neutralization by marine $\mathrm{CaCO}_{3}$. Global Biogeochem. Cycles, 12, 259-276, https://doi.org/10.1029/98GB00744.
Bezanson, J., A. Edelman, S. Karpinski, and V. Shah, 2017: Julia: A fresh approach to numerical computing. SIAM Rev., 59, 65-98, https://doi.org/10.1137/141000671.

Bryan, K., and L. J. Lewis, 1979: A water mass model of the world ocean. J. Geophys. Res., 84, 2503-2517, https://doi.org/10.1029/ jc084ic05p02503.

Callies, J., 2018: Restratification of abyssal mixing layers by submesoscale baroclinic eddies. J. Phys. Oceanogr., 48, 19952010, https://doi.org/10.1175/JPO-D-18-0082.1.

_ and R. Ferrari, 2018: Dynamics of an abyssal circulation driven by bottom-intensified mixing on slopes. J. Phys. Oceanogr., 48 , 1257-1282, https://doi.org/10.1175/JPO-D-17-0125.1.

Cember, R. P., 1998: On deep western boundary currents. J. Geophys. Res., 103, 5397-5417, https://doi.org/10.1029/97JC02422.

Cimoli, L., C.-P. Caulfield, H. L. Johnson, D. P. Marshall, A. Mashayek, A. C. N. Garabato, and C. Vic, 2019: Sensitivity of deep ocean mixing to local internal tide breaking and mixing efficiency. Geophys. Res. Lett., 46, 14 622-14 633, https://doi.org/10.1029/2019GL085056.

de Lavergne, C., G. Madec, J. Le Sommer, A. J. G. Nurser, and A. C. Naveira Garabato, 2016a: The impact of a variable mixing efficiency on the abyssal overturning. J. Phys. Oceanogr., 46, 663-681, https://doi.org/10.1175/JPO-D-14-0259.1.

,,$---\longrightarrow$, and,$- 2016 \mathrm{~b}$ : On the consumption of Antarctic bottom water in the abyssal ocean. J. Phys. Oceanogr., 46, 635-661, https://doi.org/10.1175/JPO-D-14-0201.1.

,,-- F. Roquet, R. M. Holmes, and T. J. McDougall, 2017: Abyssal ocean overturning shaped by seafloor distribution. Nature, 551, 181-186, https://doi.org/10.1038/nature24472.

Dell, R., and L. Pratt, 2015: Diffusive boundary layers over varying topography. J. Fluid Mech., 769, 635-653, https://doi.org/10.1017/ jfm.2015.88.

De Szoeke, R. A., and A. F. Bennett, 1993: Microstructure fluxes across density surfaces. J. Phys. Oceanogr., 23, 2254-2264, https:// doi.org/10.1175/1520-0485(1993)023 <2254:mfads >2.0.co;2.

Drake, H., 2020: hdrake/abyssalflow: First set of revisions. Zenodo, https://doi.org/10.5281/zenodo.3746882.

Emile-Geay, J., and G. Madec, 2009: Geothermal heating, diapycnal mixing and the abyssal circulation. Ocean Sci., 5, 203217, https://doi.org/10.5194/os-5-203-2009.

Ferrari, R., A. Mashayek, T. J. McDougall, M. Nikurashin, and J.-M. Campin, 2016: Turning ocean mixing upside down. J. Phys. Oceanogr., 46, 2239-2261, https://doi.org/10.1175/JPO-D-15-0244.1.

Garabato, A. C. N., and Coauthors, 2019: Rapid mixing and exchange of deep-ocean waters in an abyssal boundary current. Proc. Natl. Acad. Sci. USA, 116, $13233-13238$, https://doi.org/ 10.1073/pnas.1904087116.

Garrett, C., 1990: The role of secondary circulation in boundary mixing. J. Geophys. Res., 95, 3181-3188, https://doi.org/10.1029/ JC095iC03p03181.

— , P. MacCready, and P. Rhines, 1993: Boundary mixing and arrested Ekman layers: Rotating stratified flow near a sloping boundary. Annu. Rev. Fluid Mech., 25, 291-323, https:// doi.org/10.1146/annurev.fl.25.010193.001451.

Gent, P. R., and J. C. McWilliams, 1990: Isopycnal mixing in ocean circulation models. J. Phys. Oceanogr., 20, 150-155, https:// doi.org/10.1175/1520-0485(1990)020<0150:imiocm >2.0.co;2.

Gouretski, V., and K. P. Koltermann, 2004: WOCE Global Hydrographic Climatology. BSH Tech. Rep. 35, 52 pp.

Greatbatch, R. J., and K. G. Lamb, 1990: On parameterizing vertical mixing of momentum in non-eddy resolving ocean models. J. Phys. Oceanogr., 20, 1634-1637, https://doi.org/10.1175/15200485(1990)020<1634:opvmom>2.0.co;2. 
Gregg, M. C., 1989: Scaling turbulent dissipation in the thermocline. J. Geophys. Res., 94, 9686-9698, https://doi.org/10.1029/ JC094iC07p09686.

Hansen, J., G. Russell, A. Lacis, I. Fung, D. Rind, and P. Stone, 1985: Climate response times: Dependence on climate sensitivity and ocean mixing. Science, 229, 857-859, https://doi.org/ 10.1126/science.229.4716.857.

Hogg, N., P. Biscaye, W. Gardner, and W. Schmmitz Jr., 1982: On the transport and modification of Antarctic bottom water in the Vema Channel. J. Mar. Res., 40, 231-263.

Holden, P. B., N. R. Edwards, K. Fraedrich, E. Kirk, F. Lunkeit, and X. Zhu, 2016: PLASIM-GENIE v1.0: A new intermediate complexity AOGCM. Geosci. Model Dev., 9, 3347-3361, https://doi.org/10.5194/gmd-9-3347-2016.

Holmes, R. M., C. de Lavergne, and T. J. McDougall, 2018: Ridges, seamounts, troughs, and bowls: Topographic control of the dianeutral circulation in the abyssal ocean. J. Phys. Oceanogr., 48, 861-882, https://doi.org/10.1175/JPO-D-17-0141.1.

$\_, \ldots$, and — 2019: Tracer transport within abyssal mixing layers. J. Phys. Oceanogr., 49, 2669-2695, https://doi.org/ 10.1175/JPO-D-19-0006.1.

Huang, R. X., and X. Jin, 2002: Deep circulation in the South Atlantic induced by bottom-intensified mixing over the midocean ridge. J. Phys. Oceanogr., 32, 1150-1164, https://doi.org/ 10.1175/1520-0485(2002)032<1150:DCITSA > 2.0.CO;2.

Jansen, M. F., and L.-P. Nadeau, 2019: A toy model for the response of the residual overturning circulation to surface warming. J. Phys. Oceanogr., 49, 1249-1268, https://doi.org/10.1175/ JPO-D-18-0187.1.

Jayne, S. R., 2009: The impact of abyssal mixing parameterizations in an ocean general circulation model. J. Phys. Oceanogr., 39, 1756-1775, https://doi.org/10.1175/2009JPO4085.1.

Kawase, M., 1987: Establishment of deep ocean circulation driven by deep-water production. J. Phys. Oceanogr., 17, 2294-2317, https://doi.org/10.1175/1520-0485(1987)017<2294:EODOCD> 2.0.CO;2.

Koltermann, K. P., V. Gouretski, and K. Jancke, 2011: Atlantic Ocean. Vol. 3, Hydrographic Atlas of the World Ocean Circulation Experiment (WOCE), WOCE International Project Office, https://doi.org/10.21976/C6RP4Z.

Ledwell, J. R., A. J. Watson, and C. S. Law, 1993: Evidence for slow mixing across the pycnocline from an open-ocean tracerrelease experiment. Nature, 364, 701-703, https://doi.org/ 10.1038/364701a0.

_ , E. T. Montgomery, K. L. Polzin, L. C. St. Laurent, R. W. Schmitt, and J. M. Toole, 2000: Evidence for enhanced mixing over rough topography in the abyssal ocean. Nature, 403, 179182, https://doi.org/10.1038/35003164

Lumpkin, R., and K. Speer, 2007: Global ocean meridional overturning. J. Phys. Oceanogr., 37, 2550-2562, http://doi.org/ 10.1175/JPO3130.1.

MacKinnon, J. A., and Coauthors, 2017: Climate process team on internal wave-driven ocean mixing. Bull. Amer. Meteor. Soc., 98, 2429-2454, https://doi.org/10.1175/BAMS-D-160030.1 .

Marotzke, J., 1997: Boundary mixing and the dynamics of threedimensional thermohaline circulations. J. Phys. Oceanogr., 27, 1713-1728, https://doi.org/10.1175/1520-0485(1997)027<1713: bmatdo $>2.0 . c 0 ; 2$.

Marshall, J., and T. Radko, 2003: Residual-mean solutions for the Antarctic circumpolar current and its associated overturning circulation. J. Phys. Oceanogr., 33, 2341-2354, https://doi.org/ 10.1175/1520-0485(2003)033<2341:rsftac > 2.0.co;2.
— and K. Speer, 2012: Closure of the meridional overturning circulation through Southern Ocean upwelling. Nat. Geosci., 5, 171-180, https://doi.org/10.1038/ngeo1391.

- D. Jamous, and J. Nilsson, 1999: Reconciling thermodynamic and dynamic methods of computation of water-mass transformation rates. Deep-Sea Res. I, 46, 545-572, https://doi.org/ 10.1016/s0967-0637(98)00082-x.

McDougall, T. J., and R. Ferrari, 2017: Abyssal upwelling and downwelling driven by near-boundary mixing. J. Phys. Oceanogr., 47, 261-283, https://doi.org/10.1175/JPO-D-16-0082.1.

Melet, A., S. Legg, and R. Hallberg, 2016: Climatic impacts of parameterized local and remote tidal mixing. J. Climate, 29, 3473-3500, https://doi.org/10.1175/JCLI-D-15-0153.1.

Munk, W. H., 1966: Abyssal recipes. Deep Sea Res., 13, 707-730, https://doi.org/10.1016/0011-7471(66)90602-4.

- and C. Wunsch, 1998: Abyssal recipes II: Energetics of tidal and wind mixing. Deep-Sea Res. I, 45, 1977-2010, https:// doi.org/10.1016/S0967-0637(98)00070-3.

Nikurashin, M., and R. Ferrari, 2010: Radiation and dissipation of internal waves generated by geostrophic motions impinging on small-scale topography: Theory. J. Phys. Oceanogr., 40, 1055-1074, https://doi.org/10.1175/2009JPO4199.1.

— , and — 2011: Global energy conversion rate from geostrophic flows into internal lee waves in the deep ocean. Geophys. Res. Lett., 38, L08610, https://doi.org/10.1029/2011GL046576.

— ternal tides generated at rough topography. J. Phys. Oceanogr., 41, 378-395, https://doi.org/10.1175/2010JPO4522.1.

— , and G. Vallis, 2011: A theory of deep stratification and overturning circulation in the ocean. J. Phys. Oceanogr., 41, 485-502, https://doi.org/10.1175/2010JPO4529.1.

— breaking internal waves in the deep ocean. Geophys. Res. Lett., 40, 3133-3137, https://doi.org/10.1002/grl.50542.

, G. Vallis, M. Nikurashin, and G. Vallis, 2012: A theory of the interhemispheric meridional overturning circulation and associated stratification. J. Phys. Oceanogr., 42, 1652-1667, https://doi.org/10.1175/JPO-D-11-0189.1.

Nycander, J., 2005: Generation of internal waves in the deep ocean by tides. J. Geophys. Res. Oceans, 110, C10028, https://doi.org/ 10.1029/2004JC002487.

Osborn, T. R., 1980: Estimates of the local rate of vertical diffusion from dissipation measurements. J. Phys. Oceanogr., 10, 83-89, https:// doi.org/10.1175/1520-0485(1980)010<0083:eotlro >2.0.co;2.

Pedlosky, J., 1992: The baroclinic structure of the abyssal circulation. J. Phys. Oceanogr., 22, 652-659, https://doi.org/10.1175/ 1520-0485(1992)022<0652:TBSOTA $>2.0$. CO;2.

_ 1996: Ocean Circulation Theory. Springer, 453 pp., https:// doi.org/10.1007/978-3-662-03204-6.

Phillips, O. M., 1970: On flows induced by diffusion in a stably stratified fluid. Deep-Sea Res. Oceanogr. Abstr., 17, 435-443, https://doi.org/10.1016/0011-7471(70)90058-6.

_ J.-H. Shyu, and H. Salmun, 1986: An experiment on boundary mixing: Mean circulation and transport rates. J. Fluid Mech., 173, 473-499, https://doi.org/10.1017/s0022112086001234.

Polzin, K. L., 2009: An abyssal recipe. Ocean Modell., 30, 298-309, https://doi.org/10.1016/j.ocemod.2009.07.006.

, J. Toole, J. R. Ledwell, and R. Schmitt, 1997: Spatial variability of turbulent mixing in the abyssal ocean. Science, 276, 93-96, https://doi.org/10.1126/science.276.5309.93.

Rhines, P. B., 1993: Oceanic general circulation: Wave and advection dynamics. Modelling Oceanic Climate Interactions, J. Willebrand and D. L. T. Anderson, Eds., Springer, 67-149. 
Robinson, A., and H. Stommel, 1959: The oceanic thermocline and the associated thermohaline circulation. Tellus, 11, 295-308, https://doi.org/10.1111/j.2153-3490.1959.tb00035.x.

Salmon, R., 1992: A two-layer Gulf Stream over a continental slope. J. Mar. Res., 50, 341-365, https://doi.org/10.1357/ 002224092784797610.

Salmun, H., P. D. Killworth, and J. R. Blundell, 1991: A twodimensional model of boundary mixing. J. Geophys. Res., 96, 18 447-18 474, https://doi.org/10.1029/91JC01917.

Samelson, R. M., 1998: Large-scale circulation with locally enhanced vertical mixing. J. Phys. Oceanogr., 28, 712-726, https://doi.org/ 10.1175/1520-0485(1998)028<0712:lscwle >2.0.co;2.

Sarmiento, J. L., and J. R. Toggweiler, 1984: A new model for the role of the oceans in determining atmospheric $\mathrm{PCO}_{2}$. Nature, 308, 621-624, https://doi.org/10.1038/308621a0.

Sheen, K. L., and Coauthors, 2013: Rates and mechanisms of turbulent dissipation and mixing in the Southern Ocean: Results from the Diapycnal and Isopycnal Mixing Experiment in the Southern Ocean (DIMES). J. Geophys. Res. Oceans, 118, 2774-2792, https://doi.org/10.1002/jgrc.20217.

St. Laurent, L. C., and C. Garrett, 2002: The role of internal tides in mixing the deep ocean. J. Phys. Oceanogr., 32, 2882-2899, https:// doi.org/10.1175/1520-0485(2002)032<2882:troiti >2.0.co;2.

_ J. M. Toole, and R. W. Schmitt, 2001: Buoyancy forcing by turbulence above rough topography in the abyssal Brazil basin. J. Phys. Oceanogr., 31, 3476-3495, https://doi.org/10.1175/ 1520-0485(2001)031<3476:BFBTAR >2.0.CO;2.

Stommel, H., 1948: The westward intensification of wind-driven ocean currents. Trans. Amer. Geophys. Union, 29, 202, https:// doi.org/10.1029/TR029i002p00202.

__ 1957: The abyssal circulation of the ocean. Nature, 180, 733-734, https://doi.org/10.1038/180733a0.

—_, and A. B. Arons, 1959a: On the abyssal circulation of the world ocean-I. Stationary planetary flow patterns on a sphere. Deep-Sea Res., 6, 140-154, https://doi.org/10.1016/ 0146-6313(59)90065-6.

— ocean-II. An idealized model of the circulation pattern and amplitude in oceanic basins. Deep-Sea Res., 6, 217-233, https:// doi.org/10.1016/0146-6313(59)90075-9.

Sverdrup, H., M. Johnson, and R. Fleming, 1942: The oceans: Their physics, chemistry and general biology. Oceanography, 34, 170, https://doi.org/10.2307/210609.

Talley, L. D., 2007: Pacific Ocean. Vol. 2, Hydrographic Atlas of the World Ocean Circulation Experiment (WOCE), WOCE International Project Office, https://doi.org/10.21976/C6WC77. 2013a: Closure of the global overturning circulation through the Indian, Pacific, and Southern Oceans: Schematics and transports. Oceanography, 26, 80-97, https://doi.org/10.5670/ oceanog.2013.07.

_ 2013b: Indian Ocean. Vol. 4, Hydrographic Atlas of the World Ocean Circulation Experiment (WOCE), International WOCE Project Office, https://doi.org/10.21976/C61595.

Thompson, A. F., A. L. Stewart, and T. Bischoff, 2016: A multibasin residual-mean model for the global overturning circulation. J. Phys. Oceanogr., 46, 2583-2604, https://doi.org/10.1175/ JPO-D-15-0204.1.

Thompson, L., and G. C. Johnson, 1996: Abyssal currents generated by diffusion and geothermal heating over rises. Deep-Sea Res. I, 43, 193-211, https://doi.org/10.1016/09670637(96)00095-7.

Thorpe, S. A., 1987: Current and temperature variability on the continental slope. Philos. Trans. Roy. Soc. London, 323A, 471-517, https://doi.org/10.1098/rsta.1987.0100.

Thurnherr, A. M., and K. G. Speer, 2003: Boundary mixing and topographic blocking on the mid-Atlantic ridge in the South Atlantic. J. Phys. Oceanogr., 33, 848-862, https://doi.org/ 10.1175/1520-0485(2003)33<848:bmatbo $>2.0$. co;2.

_ L. C. St. Laurent, K. G. Speer, J. M. Toole, and J. R. Ledwell, 2005: Mixing associated with sills in a canyon on the midocean ridge flank. J. Phys. Oceanogr., 35, 1370-1381, https://doi.org/ 10.1175/JPO2773.1.

Toggweiler, J. R., K. Dixon, and K. Bryan, 1989: Simulations of radiocarbon in a coarse-resolution World Ocean model: 1. Steady state prebomb distributions. J. Geophys. Res., 94, 8217-8242, https://doi.org/10.1029/JC094iC06p08217.

Walin, G., 1982: On the relation between sea-surface heat flow and thermal circulation in the ocean. Tellus, 34, 187-195, https:// doi.org/10.3402/tellusa.v34i2.10801.

Waterhouse, A. F., and Coauthors, 2014: Global patterns of diapycnal mixing from measurements of the turbulent dissipation rate. J. Phys. Oceanogr., 44, 1854-1872, https:// doi.org/10.1175/JPO-D-13-0104.1.

Wenegrat, J. O., J. Callies, and L. N. Thomas, 2018: Submesoscale baroclinic instability in the bottom boundary layer. J. Phys. Oceanogr., 48, 2571-2592, https://doi.org/10.1175/JPO-D-17-0264.1.

Wunsch, C., 1970: On oceanic boundary mixing. Deep-Sea Res. Oceanogr. Abstr., 17, 293-301, https://doi.org/10.1016/00117471(70)90022-7.

Young, W. R., 2012: An exact thickness-weighted average formulation of the Boussinesq equations. J. Phys. Oceanogr., 42, 692707, https://doi.org/10.1175/JPO-D-11-0102.1. 